\title{
Identification of Rub and Unbalance in 320-MW Turbogenerators
}

\author{
N. Bachschmid, P. Pennacchi, and A. Vania \\ Dipartimento di Meccanica, Politecnico di Milano, Milano, Italy
}

\author{
G. A. Zanetta and L. Gregori \\ Business Unit Generation, CESI-S.p.A., Segrate (MI), Italy
}

This article presents two experiences of application of a model-based fault identification method on real machines. The first case presented is an unbalance identification on a 320-MW turbogenerator unit operating in a fossil power plant. In the second case, concerning a machine of the same size but of a different manufacturer, the Low Pressure (LP) turbine was affected by a rub in the sealings and this time, the fault was modeled by local bows. The identification of the faults is performed by means of a model-based identification technique in frequency domain, suitably modified in order to take into account simultaneous faults. The theoretical background of the applied method is briefly illustrated and some considerations also are presented about the best choice of the rotating speed set of the run-down transient to be used for an effective identification and about the appropriate weighting of vibration measurements at the machine bearings.

Keywords Diagnostics, Identification, Multiple-faults, Rotordynamics, Rub, Unbalance

Fault detection and diagnosis in rotating machinery is a very important topic of rotordynamics and many studies are present in literature. A complete review of the fault types considered, the identification methods employed, the machine types, and the case histories are too numerous to list. However, some useful references can be obtained from Isermann (1995) which has presented a very detailed survey of the possible methods employed

Received 25 June 2002; accepted 1 July 2002.

Address correspondence to P. Pennacchi, Dipartimento di Meccanica, Politecnico di Milano, Campus Bovisa, Via la Masa, 34, Milano, Italy I-20158. E-mail: paolo.pennacchi@ polimi.it

in general technical processes, both for detection and diagnosis. By sticking to the rotordynamics field and limiting oneself to the most recent literature contributions, two main approaches can be used.

In the first approach, the symptoms can be defined using qualitative information, based on human operators' experience, which creates a knowledge base used for fault detection. A recent contribution is given in White and Jecmenica (1999): an expert system can be built up, in which different diagnostic reasoning strategies can be applied. Fault-symptom matrices, fault-symptom trees, if-then rules, or fuzzy logic classifications can be used to indicate in a probabilistic approach the type, and sometimes also the size and location of the most probable fault. Artificial neural networks (ANN) also can be used for creating the symptom-fault correlation or to forecast vibrational behavior (see Gregori and Zanetta, 2001). This qualitative diagnostic approach is widely used in both industrial environments and advanced research work.

The second approach is quantitative and is called the modelbased fault detection method. In this case, a reliable model of the system, or the process, is used to create the symptom-fault correlation or the input-output relation. However, this method has many different ways of application. Among recent contributions available in literature, Mayes and Penny (1999) introduced a fuzzy clustering method in which the basis is to consider the vibration data as a high-dimension feature vector and the vibration caused by a particular fault on a specific machines can be considered to be a point in this high-dimension space. This same fault, on a number of similar machines, should produce a cluster of point in the high-dimension space that is distinct from other clusters produced by different faults. The main drawback of this method is the availability of a large database on the dynamic behavior of similar machines, which can emphasize the differences in the response of similar machines.

In other applications, the fault detection can be performed by means of different model-based approaches, according to the 
nature of the system under observation:

- Parameter estimation: When the characteristic constant parameters of the process or of the components are affected by the fault.

- State estimation: When the constant parameters are unaffected by possible faults and only the state of the system, which is represented by a set of generally unmeasurable state variables (function of time), is affected by the faults. In this case the model acts as a state observer.

- Parity equations: When the faults affect some of the unmeasurable input variables, the parameters are constant, and only output variables are measured and compared with calculated model output variables.

A modal expansion of the frequency response function of the system, on both numerical model and experimental results, is used in Kreuzinger-Janik and Irretier (2000) to identify the unbalance distribution on a test-rig rotor. In Markert et al. (2000) and Platz et al. (2000) the authors present a model and simulated results in which equivalent loads due to the faults (rubbing and unbalances) are virtual forces and moments acting on the linear undamaged system model to generate a dynamic behavior identical to the measured one of the damaged system. The identification is then performed by least square fitting in the time domain. In Edwards et al. (2000), a model-based identification in the frequency domain is employed to identify an unbalance on a test-rig. A balancing method for nonlinear rotor bearing systems with hydrodynamic bearings, which uses the unbalance response measured at a discrete number of measurement planes, is presented in Chen et al. (2001) and applied on numerical results. In Patton et al. (2001) a complex framework of modelbased identification techniques are applied on numerical results of a gas turbine.

A more comprehensive approach, able to identify several different types of faults and to discriminate among faults which generate similar harmonic components, has been introduced in Bachschmid and Pennacchi (2000). This method has been experimentally validated on different test-rigs and some real machines (see Bachschmid et al., 1999; Bachschmid et al., 2000 a,b,c,d; Vania et al., 2001) with many types of faults, such as unbalances, rotor permanent bows, rotor rubs, coupling misalignments, cracks, journal ovalization, and rotor stiffness asymmetries.

However it appears, among all the literature studies with few exceptions, the proposed methods are tested only numerically or on a small scale test-rig. This is normally due to the possibility of an easy evaluate of the actual fault amount, especially as regards to the unbalance. In this article a model-based identification method in frequency domain, able to handle also multiple simultaneous faults, is applied on experimental data of two different 320-MW turbogenerators.

In the first case study, an unbalance identification is presented, even if this case would be more correctly described as balancing mass identification. Since in this case it is possible to know all the fault-relevant parameters, i.e., position, module, and phase, a rather accurate sensitivity analysis has been performed considering different models of the rotor, tuned on one of the experimental critical speeds, different rotating speed sets, weights for the vibrations in the bearings of the machine, and also considering the nodes where these vibrations are measured.

In the second case, a rub on a LP turbine is presented. In this case the position of the rub on the LP turbine resulted in uncertainty: The most probable location was close to bearing \#3 or \#4. Only the visual inspection made during the maintenance operation of the machine that has followed its stopping, allowed the to discovery of exactly where the rub had occurred.

\section{MODEL-BASED IDENTIFICATION OF MULTIPLE FAULTS IN FREQUENCY DOMAIN}

In the model-based identification procedure, input variables are the exciting forces and output variables are the vibrations. The procedure requires the model definition of the elements (rotors, bearings, supporting structure) that compose the rotor system. A finite beam element model is assumed for the rotor, the bearings are represented by means of their stiffness and damping matrices (therefore nonlinear oil film effects are neglected), while several representations can be given for the foundation, such as modal, elasto-dynamic matrix, or lumped springs and dampers. The effect of the faults also has to be modeled and this is done by introducing an equivalent system of external forces and moments. A more detailed analysis is reported in Bachschmid et al. (2000b, 2002).

In regards to the experimental data, vibration differences between a reference case and the considered one are used. This way, if the system can be considered as linear, the vibrational behavior is due to the developing fault only. In fact, with reference to the standard matrix equation of the system

$$
\mathbf{M} \ddot{\mathbf{x}}_{t}+\mathbf{D} \dot{\mathbf{x}}_{t}+\mathbf{K} \mathbf{x}_{t}=\mathbf{F}(t)
$$

The arising fault causes changes $d \mathbf{M}, d \mathbf{D}$, and $d \mathbf{K}$ in mass $\mathbf{M}$, damping $\mathbf{D}$, and stiffness $\mathbf{K}$ matrices. Since in real machines only few measuring points along the shaft, usually in the bearings, are available, it seems difficult to identify these changes from the measurement of vibration $\mathbf{x}_{t}$. Equation (1) yields

$$
\begin{aligned}
& (\mathbf{M}+d \mathbf{M}) \ddot{\mathbf{x}}_{t}+(\mathbf{D}+d \mathbf{D}) \dot{\mathbf{x}}_{t}+(\mathbf{K}+d \mathbf{K}) \mathbf{x}_{t} \\
& \quad=\mathbf{W}+\left(\mathbf{U}+\mathbf{M}_{u}\right) e^{i \Omega t}
\end{aligned}
$$

in which the right-hand side external forces $\mathbf{F}(t)$ are generally unknown, because they are composed by the weight (which is known) and the original unbalance and bow (which are unknown). If the system is considered as linear, then the total vibration $\mathbf{x}_{t}$ can be be split into two terms which can be simply superposed:

$$
\mathbf{x}_{t}=\mathbf{x}_{1}+\mathbf{x}
$$


The first vibration vector $\mathbf{x}_{1}$ is due to the weight $\mathbf{W}$ as well as to the unknown unbalance force $\mathbf{U} e^{i \Omega t}$ and unbalance moment $\mathbf{M}_{u} e^{i \Omega t}$, and the second term $\mathbf{x}$ is due to the fault. The component $\mathbf{x}$ may be obtained by calculating the vector differences of the actual vibrations $\mathbf{x}_{t}$ (due to weight, original unbalance, and fault) minus the original vibrations $\mathbf{x}_{1}$ measured, in the same operating conditions (rotation speed, flow rate, power, temperature, etc.), before the fault occurrence. Recalling the definition of $\mathbf{x}_{1}$, the pre-fault vibration, the following equation holds:

$$
\mathbf{M} \ddot{\mathbf{x}}_{1}+\mathbf{D} \dot{\mathbf{x}}_{1}+\mathbf{K} \mathbf{x}_{1}=\mathbf{W}+\left(\mathbf{U}+\mathbf{M}_{u}\right) e^{i \Omega t}
$$

which substituted in Equation (2) gives:

$$
\mathbf{M} \ddot{\mathbf{x}}+\mathbf{D} \dot{\mathbf{x}}+\mathbf{K x}=-d \mathbf{M} \ddot{\mathbf{x}}_{t}-d \mathbf{D} \dot{\mathbf{x}}_{t}-d \mathbf{K} \mathbf{x}_{t}
$$

The right-hand side of Equation (5) can be considered as a system of equivalent external forces, which force the fault-free system to have the change in vibrations defined by $\mathbf{x}$, that is due to the developing fault only:

$$
\mathbf{M} \ddot{\mathbf{x}}+\mathbf{D} \dot{\mathbf{x}}+\mathbf{K x}=\mathbf{F}_{f}(t)
$$

Using this last approach, the problem of fault identification is then reduced to a force identification procedure with known system parameters, keeping in mind that a particular force system corresponds to each type of fault considered. Since the final goal is the identification of faults, this approach is preferred since only few elements of the unknown fault-forcing vector are in reality different from zero, which significantly reduces the number of unknowns to be identified. In fact, the forces that model each fault are considered to be applied in not more than two different nodes along the rotor. If we consider a steady-state situation, keeping in mind that also a slow run down transient can be considered to be a succession of steady-state situations, assuming linearity of the system and applying the harmonic balance criteria from Equation (6), we get, for each harmonic component, the equations:

$$
\left[-(n \Omega)^{2} \mathbf{M}+i n \Omega \mathbf{D}+\mathbf{K}\right] \mathbf{X}_{n}=\mathbf{F}_{f_{n}}(\Omega)
$$

where the force vector $\mathbf{F}_{f_{n}}$, has to be identified. This force vector could be a function of $\Omega$ or not depending on the type of fault. If the presence of several faults (f.i. $m$ faults) is considered, then the force vector $\mathbf{F}_{f_{n}}$ is composed by several vectors $\mathbf{F}_{f_{n}}^{(1)}$, $\mathbf{F}_{f_{n}}^{(2)}, \ldots, \mathbf{F}_{f_{n}}^{(m)}$ :

$$
\mathbf{F}_{f_{n}}(\Omega)=\sum_{i=1}^{m} \mathbf{F}_{f_{n}}^{(i)}(\Omega)
$$

Generally, the fault identification procedure is started when the vibration vector change exceeds a suitable pre-established acceptance region; in this case, it is more likely that the change in the vibrational behavior is really caused by an impeding fault only. Anyway, the case of multiple faults may occur in real machines: sometimes a bow (due to several different causes) and an unbalance or a coupling misalignment may develop simultaneously. Another case of multiple faults identification can be considered when the reference situation $\mathbf{x}_{1}$ is not available, then the arising fault is superposed to the original unbalance and bow distribution. In this case, the multiple fault identification also may be useful for selecting the developing fault and the original unbalance and bow.

Few spectral components $\mathbf{X}_{n}$ in the frequency domain (generally not more than three, in absence of rolling bearings and gears), measured in correspondence of the bearings, represent completely the periodical vibration time history.

Moreover, the $k$ th fault acts on few degree of freedom (d.o.f.) of the system, so that the vector $\mathbf{F}_{f_{n}}^{(k)}$ is not a full-element vector which is convenient to be represented by:

$$
\mathbf{F}_{f_{n}}^{(k)}(\Omega)=\left[\mathbf{F}_{L}^{(k)}\right] \mathbf{A}^{(k)}(\Omega)
$$

where $\left[\mathbf{F}_{L}^{(k)}\right]$ is the localization vector, which has all nullelements except for the d.o.f. to which the forcing system is applied, and $\mathbf{A}^{(k)}(\Omega)$ is the complex vector of the identified defects. The localization vector gives the position of the fault along the rotor and expresses the link between the force fault system and the modulus and phase of the identified fault that produce it.

Many fault models have been introduced that correspond to common faults that occurred in real machines, see i.e., Bachschmid and Pennacchi (2000), Bachschmid et al. (2002), and Platz and Markert (2001). In this article, it is sufficient to consider only the unbalance and the rub.

The unbalance has only a $1 \mathrm{x}$ rev. component. The complex vector of the general $k^{\text {th }}$ fault force system becomes in this case:

$$
\mathbf{F}_{f_{1}}^{(k)}=[0 \vdots 10 i 0 \vdots 0]^{\mathrm{T}} \cdot(m r)^{(k)} \Omega^{2} e^{i \varphi^{(k)}}=\left[\mathbf{F}_{L}^{(k)}\right] \mathbf{A}^{(k)}(\Omega)
$$

where the only elements different from zero are the ones relative to the horizontal and vertical d.o.f. of the node $j$, where the unbalance is supposed to be applied. Note that in this case the fault force system is a function of the rotating speed $\Omega$.

Rub modeling is not so straightforward as unbalance. Often, nonlinear effects are present and characteristic behaviors like the "Newkirk" effect can be observed (Vania et al. (2001); Kellenberger (1980); Liebich (1998); Bachschmid et al. (2001)). In general, rub determines an asymmetrical heating of a symmetrical rotor, which causes an asymmetrical axial strain distribution on the cross section and the shaft bows. The asymmetrical heating can be localized when it is due to a full annular rub (local bow), or extended to a certain length of the rotor, as in a generator when a cooling duct is obstructed (extended bow). For diagnostics purposes, a bow can be simulated, generally in a fairly accurate way, by imposing on the rotor, in only two nodes of the finite element (f.e.) model, a suitable system of rotating and speed independent bending moments. These generate the 
same (polarly asymmetrical) strains, the same static deflection and, dynamically, at the operating speed, the total vibration of the shaft. Therefore in each one of the two nodes of the f.e. model (the extremity nodes of the part of the rotor which is interested by the bow) only one rotating moment is applied, in order to have an easier identification procedure.

The complex vector of the fault force system $\mathbf{F}_{f_{1}}^{(k)}$, which simulates the $k$ th bow, and the corresponding $\left[\mathbf{F}_{L}^{(k)}\right]$ and $\mathbf{A}^{(k)}$ become:

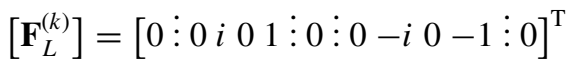

$$
\begin{aligned}
& \mathbf{A}^{(k)}=M^{(k)} e^{i \varphi^{(k)}}
\end{aligned}
$$

where the only elements different from zero are the ones relative to the horizontal and vertical rotational d.o.f. of two nodes. However, in this case, the diagnostic significance of the identified fault is mainly in its location, while the knowledge of the bending moments cannot be used directly since they do not correspond to anything actually measured on the machines. They can, however, be used to simulate the machine behavior and to compare it with the experimental one.

Finally, Equation (7) can be rewritten, for each harmonic component, in the following way:

$$
[\mathbf{E}(n \Omega)] \mathbf{X}_{n}=\sum_{i=1}^{m} \mathbf{F}_{f_{n}}^{(i)}(\Omega)=\mathbf{F}_{f_{n}}(\Omega)
$$

where $[\mathbf{E}(n \Omega)]$ is the system dynamical stiffness matrix for the speed $\Omega$ and for the $n$th harmonic component. These days, experimental vibration data of real machines (Gregori et al., 2000) are often collected by condition monitoring systems and are available for many rotating speeds, typically those of the run-down transient that, in large turbogenerators of power plants, occur with slowly changing speed, due to the high inertia of the system, so that actually the transient can be considered as a series of different steady-state conditions. This allows these data to be used in the frequency domain. The identification method can be applied for a set of $p$ rotating speeds that can be organized as a vector:

$$
\vec{\Omega}=\left[\Omega_{1} \Omega_{2} \cdots \Omega_{p}\right]^{\mathrm{T}}
$$

Then matrix and vectors of Equation (12) have to be expanded:

$$
[\mathbf{E}(n \overrightarrow{\boldsymbol{\Omega}})] \mathbf{X}_{n}=\left[\begin{array}{cccc}
\mathbf{E}\left(n \Omega_{1}\right) & 0 & 0 & 0 \\
0 & \mathbf{E}\left(n \Omega_{2}\right) & 0 & 0 \\
\vdots & \vdots & \vdots & \vdots \\
0 & 0 & 0 & \mathbf{E}\left(n \Omega_{p}\right)
\end{array}\right]\left[\begin{array}{c}
\mathbf{X}_{n} \\
\mathbf{X}_{n} \\
\vdots \\
\mathbf{X}_{n}
\end{array}\right]
$$

$$
=\left[\begin{array}{c}
\sum_{i=1}^{m} \mathbf{F}_{f_{n}}^{(i)}\left(\Omega_{1}\right) \\
\sum_{i=1}^{m} \mathbf{F}_{f_{n}}^{(i)}\left(\Omega_{2}\right) \\
\vdots \\
\sum_{i=1}^{m} \mathbf{F}_{f_{n}}^{(i)}\left(\Omega_{p}\right)
\end{array}\right]=\mathbf{F}_{f_{n}}(\overrightarrow{\boldsymbol{\Omega}})
$$

Under a formal point of view, it is unimportant to consider one or $p$ rotating speeds in the identification. The fault vector is the sum of all the faults that affect the rotor as stated in Equation (8). Matrix $[\mathbf{E}(n \vec{\Omega})]$ can be inverted and Equation (12) becomes

$$
\mathbf{X}_{n}=[\mathbf{E}(n \vec{\Omega})]^{-1} \cdot \mathbf{F}_{f_{n}}(\overrightarrow{\boldsymbol{\Omega}})=\boldsymbol{\alpha}_{n}(\overrightarrow{\boldsymbol{\Omega}}) \cdot \mathbf{F}_{f_{n}}(\overrightarrow{\boldsymbol{\Omega}})
$$

where $\boldsymbol{\alpha}_{n}(\overrightarrow{\boldsymbol{\Omega}})$ is the inverse of $[\mathbf{E}=(\boldsymbol{n} \overrightarrow{\boldsymbol{\Omega}})]$. Reordering in a suitable way the lines in Equation (15), by partitioning the inverse of the system dynamical stiffness matrix and omitting from $\boldsymbol{\alpha}_{n}$ and $\mathbf{F}_{f_{n}}$ the possible dependence on $\vec{\Omega}$ for conciseness, we obtain:

$$
\left\{\begin{array}{l}
\mathbf{X}_{B_{n}}=\boldsymbol{\alpha}_{B_{n}} \cdot \mathbf{F}_{f_{n}} \\
\mathbf{X}_{A_{n}}=\boldsymbol{\alpha}_{A_{n}} \cdot \mathbf{F}_{f_{n}}
\end{array}\right.
$$

where $\mathbf{X}_{B_{n}}$ is the complex amplitude vector representing the measured absolute vibrations in correspondence to the measuring sections and $\mathbf{X}_{A_{n}}$ is the vector of the remaining d.o.f. of the rotor system model.

Using the first set of Equations (16), the differences $\vec{\delta}_{n}$, between calculated vibrations $\mathbf{X}_{B_{n}}$ and measured vibrations $\mathbf{X}_{B m_{n}}$ can be defined, for each harmonic component, as:

$$
\overrightarrow{\boldsymbol{\delta}}_{n}=\mathbf{X}_{B_{n}}-\mathbf{X}_{B m_{n}}=\boldsymbol{\alpha}_{B_{n}} \cdot \mathbf{F}_{f_{n}}-\mathbf{X}_{B m_{n}}
$$

The number of equations $n_{E}$ (number of measured d.o.f.) is lower than the number $n_{F}$ (number of d.o.f. of the complete system model) which is also the number of elements of $\mathbf{F}_{f_{n}}$. But, as said before, $\mathbf{F}_{f_{n}}$ becomes a vector with many null-elements, even if the fault is not one only, so that the number of unknown elements of $\mathbf{F}_{f_{n}}$ is smaller than the number of equations. The system therefore has not a single solution for all the equations and we have to use the least square approach in order to find the solution (identified fault) that minimizes the differences which are calculated for all the different rotating speeds which are taken into consideration. Moreover, it is also useful to introduce a weighting of each of the measured vibrations, in order to give less relevance to those, which are not significant or can be affected by errors.

A scalar relative residue may be defined by the root of the ratio of the squared $\vec{\delta}_{n}$, divided by the sum of the squared measured vibration amplitudes $\mathbf{X}_{B m_{n}}$ :

$$
\boldsymbol{\delta}_{r_{n}}=\left(\frac{\left[\boldsymbol{\alpha}_{B_{n}} \cdot \mathbf{F}_{f_{n}}-\mathbf{X}_{B m_{n}}\right]^{* \mathrm{~T}}\left[\boldsymbol{\alpha}_{B_{n}} \cdot \mathbf{F}_{f_{n}}-\mathbf{X}_{B m_{n}}\right]}{\mathbf{X}_{B m_{n}}^{* \mathrm{~T}} \mathbf{X}_{B m_{n}}}\right)^{1 / 2}
$$




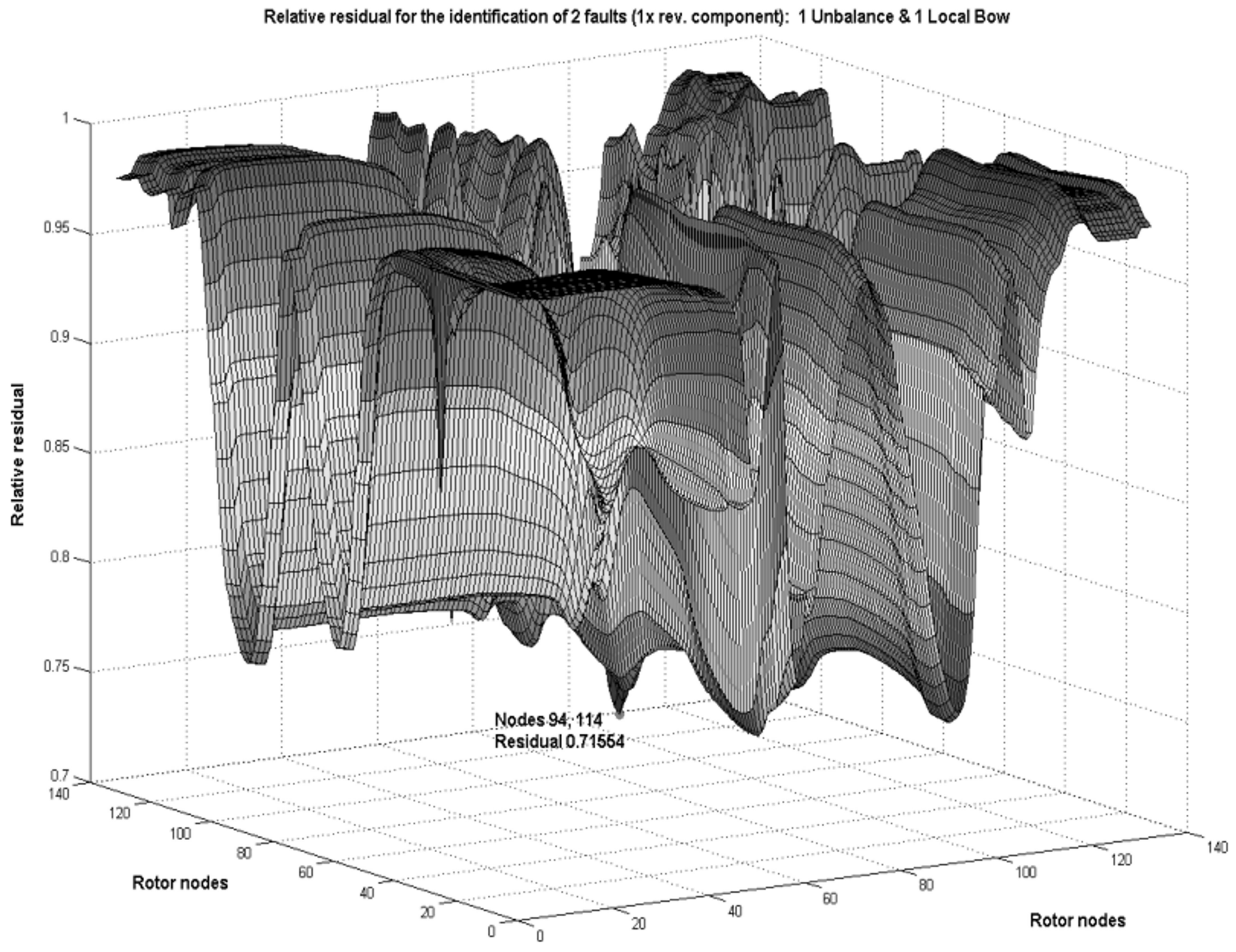

FIGURE 1

Residue surface.

By means of the hypothesis of localization of the fault, the residue is calculated for each possible node of application of each defect. This fact implies that, if we indicate with $z_{k}$ the abscissa along the rotor in correspondence to the $k$ th fault among $m$ faults, the relative residue in Equation (18) is a surface in a $\mathbb{R}^{m+1}$ space, in other terms:

$$
\delta_{r_{n}}=f\left(z_{1}, z_{2}, \ldots, z_{k}, \ldots, z_{m}\right)
$$

Where the residue reaches its minimum, i.e., the minimum of the surface in Equation (19), there is the most probable position of the fault. Figure 1 shows a sample of the residue surface, in the case of two faults.

The corresponding values of $\mathbf{F}_{f_{n}}$ give the modulus and the phase of the identified faults. The identification procedure is im- plemented in the code ADVANT (Automatic Diagnosis by Vibration ANalysis of Turbogenerator rotors) that has been used in the case studies presented in this article. The relative residue also gives an estimate of the quality of the identification, since when it results the closer to zero the better the identified fault corresponds to the actual one; this follows easily from the analysis of Equation (18).

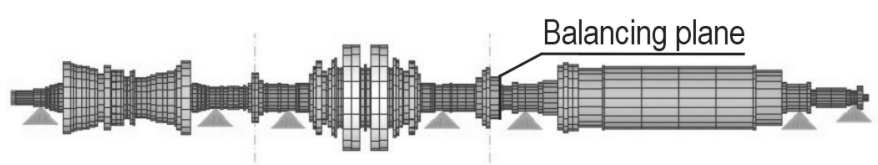

FIGURE 2

320-MW turbogenerator model used for unbalance identification. 


\section{UNBALANCE IDENTIFICATION ON A 320 MW TURBOGENERATOR}

The first case presented is related to a 320-MW turbogenerator (see Figure 2) composed of by two turbines, an HP-IP and a LP, and a generator connected by rigid couplings, on seven oil film bearings of which those on the HP-IP turbine are tilting-pads, those on LP turbine cylindrical, the first two on generator lemon-shaped, and the last tilting-pad, operating at a rated speed of $3000 \mathrm{rpm}$. The rotor, which is long at about $28 \mathrm{~m}$ and has a mass of about $131 \mathrm{t}$ ( $26 \mathrm{t}$ for the HP-IP turbine, $53 \mathrm{t}$ for the LP turbine, and $52 \mathrm{t}$ for the generator), has been modeled by 167 f.e. beams. The bearing stiffness and damping coefficients are defined for several rotating speeds in the range 300-3000 rpm, while the foundation is modeled by mass, spring, and damper systems, whose parameters are defined for several rotating speeds in the range 300-3000 rpm too.

The ADVANT code has been employed on this machine to identify a force due to a mass added for balancing, which was performed by adding a 630-g mass at a radial distance of $406 \mathrm{~mm}$ from the rotating axis, thus giving an unbalance of $0.256 \mathrm{kgm}$, on the coupling between the LP turbine and the generator, on the coupling face toward the generator. The corresponding model node is the 132, while, considering ADVANT code angle convention, the phase is $-22.5^{\circ}$ (Figure 3 ).

The experimental data sets available for this turbogroup are related to four different run-downs of the machine from normal operating condition, two of which are considered as reference cases since they were made before the balancing, and two as the faulty case since they were made after the balancing. Before using them for the identification, the data have been screened taking into account the values of the vibration differences on all the possible combinations between the reference and faulty cases. Then, only four typical rotating speeds were considered $(1500,2000,2500$, and $3000 \mathrm{rpm})$ equally spaced in the frequency range in which the system response to unbalance is significant; the effect of the balancing mass at lower rotating speed could not be appreciable. The analysis has given the following results in terms of percentage deviation from the average of the four vibration differences:

- Maximum absolute deviation on all the vibrations (normalized on bearing \#1 vertical vibration): $296 \%$

- Minimum absolute deviation on all the vibrations (normalized on bearing \#5 vertical vibration): $1.34 \%$

- Maximum average deviation on all the vibration and all the differences: $168 \%$

- Minimum average deviation on all the vibrations and all the differences: $6 \%$

- Average deviation on all the vibrations and all the differences: $48 \%$

- Average deviation on all the vibrations of bearing \#1, $\# 2$, and \#7 and all the differences: $83 \%$

- Average deviation on all the vibrations of bearing \#3, \#4, \#5, and \#6 and all the differences: 22\%

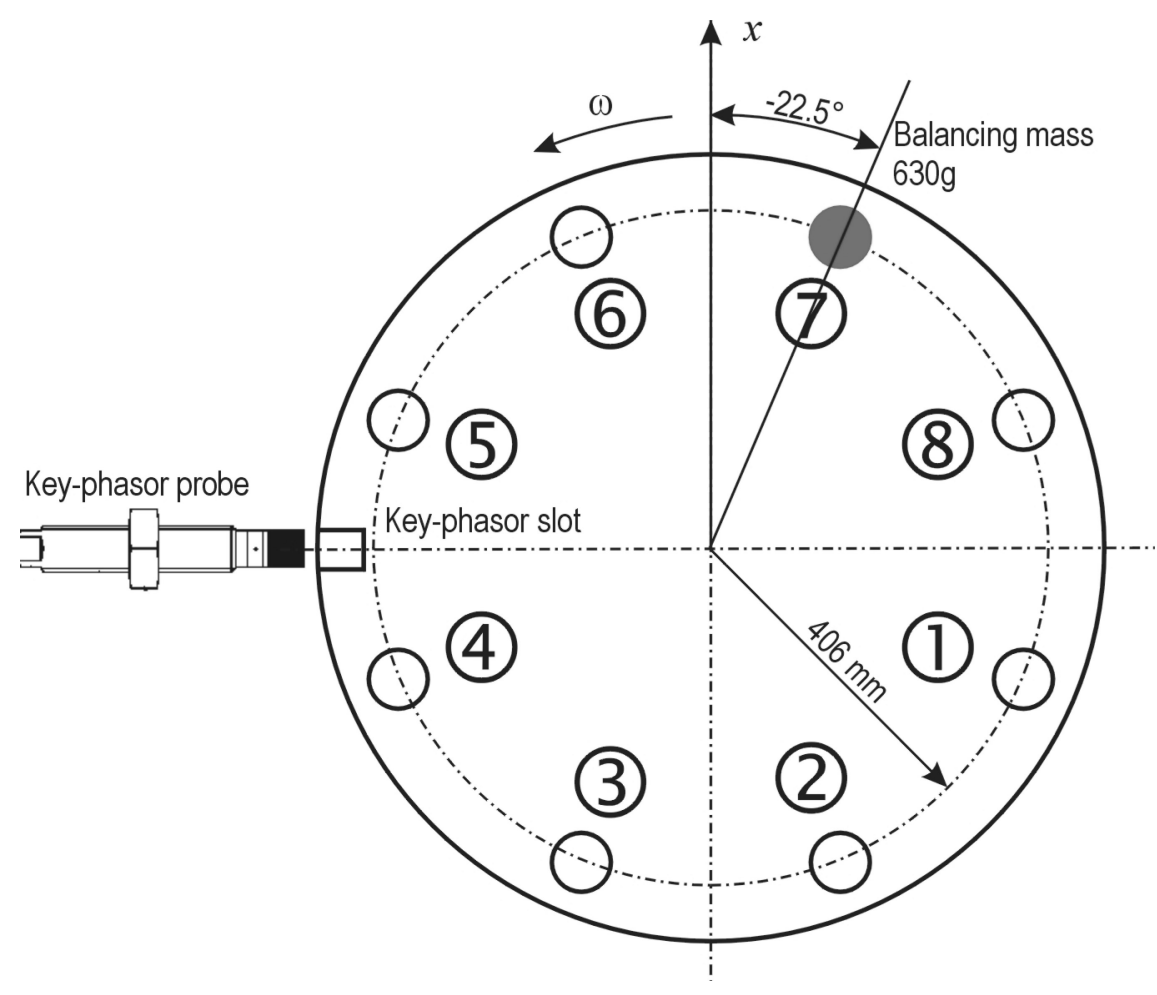

FIGURE 3

Balancing mass position. 
TABLE 1

Unbalance case-experimental and model critical speeds for the turbines and the generator

\begin{tabular}{|c|c|c|c|c|c|c|c|c|c|c|c|c|}
\hline & \multicolumn{4}{|c|}{ HP-IP turbine } & \multicolumn{4}{|c|}{ LP turbine } & \multicolumn{4}{|c|}{ Generator } \\
\hline & \multicolumn{2}{|c|}{1 st } & \multicolumn{2}{|c|}{ 2nd } & \multicolumn{2}{|c|}{$1 \mathrm{st}$} & \multicolumn{2}{|c|}{ 2nd } & \multicolumn{2}{|c|}{1 st } & \multicolumn{2}{|c|}{ 2nd } \\
\hline & $\mathrm{H}$ & V & $\mathrm{H}$ & V & $\mathrm{H}$ & V & $\mathrm{H}$ & V & $\mathrm{H}$ & V & $\mathrm{H}$ & V \\
\hline Experimental & 1560 & 1580 & $>3000$ & $>3000$ & 1230 & 1770 & 2350 & $?$ & 825 & $?$ & 2175 & 2565 \\
\hline Model A & 1830 & 1830 & 3850 & 3850 & 1570 & 1470 & 3380 & 3230 & 1000 & 980 & 2710 & 2620 \\
\hline Model B & 1600 & 1640 & 4470 & 4490 & 1480 & 1690 & 3130 & 3530 & 900 & 1010 & 2150 & 2550 \\
\hline Model C & 1580 & 1630 & 4450 & 4490 & 1260 & 1690 & 2390 & 2850 & 860 & 1010 & 2170 & 2560 \\
\hline Model D & 1570 & 1630 & 4450 & 4490 & 1260 & 1690 & 2490 & 3390 & 870 & 1010 & 2170 & 2550 \\
\hline Model E & 1580 & 1620 & 4440 & 4490 & 1260 & 1680 & 2370 & 3310 & 870 & 1010 & 2170 & 2550 \\
\hline
\end{tabular}

This analysis suggests giving a small weight, or to not consider at all the data of bearing \#1, \#2, and \#7 and indicates that the expected result of the identification cannot be considered as an absolute value, but should be related to the quality of the experimental data. In this case, excluding data of bearing \#1, \#2, and $\# 7$, the quality can be measured by the $22 \%$ of the average deviation on all the vibration differences.

Then, the rotor machine model has been tuned, using the DYNARO (DYNamic Analysis of ROtors) code, and different models were prepared. By considering the experimental results (see Table 1), it was actually not possible to exactly identify all the critical rotating speeds on the considered turbogenerator. In particular, the second critical speed of the LP turbine in the vertical direction, which on this kind of machine is in a range of $\pm 10 \%$ of the operating speed, was not identified so as the critical speeds in the horizontal and vertical directions of the second mode of the HP-IP turbine. Moreover, it is worthwhile to note that the frequency response in the range of $2500-3000 \mathrm{rpm}$ is mainly due to a mode with a maximum on the coupling between the LP turbine and the generator, whose critical speed is higher than $3000 \mathrm{rpm}$.

Five different models of the rotor have been considered, each of which is different from the other in regards to the critical speeds of the rotor sections (see Table 1) and the modal dampings sometimes. Model A was already used in previous analysis, since it is one of the most common in Italian power stations and has not been tuned at all before implementing it in ADVANT. Model B to Model E are more carefully tuned on the experimental data and differ especially on the values of the second critical speeds of the LP turbine. As an example, Figures 4 to 7 show some mode shapes for model E obtained by DYNARO. Table 2 also reports the critical speed values corresponding to the mode (see Figure 8) that has a maximum on the coupling between the LP turbine and the generator.

In regards to the choice of the rotating speed set at which the corresponding measures are used for the identification, the above s-d mentioned set of $1500,2000,2500$, and $3000 \mathrm{rpm}$ were employed or, alternatively, the set of all the available speeds.

Several identifications have been preformed using ADVANT, considering different models of the rotor, weights of the experimental data, rotating speed sets, and measuring planes. In regards to the latter aspect of interest in the element of the model in which the experimental measure are considered to be taken, two hypotheses have been introduced. In the first case the position of the measuring plane is in the middle of the bearing, and in the second, it is as close as possible to the actual measuring plane.

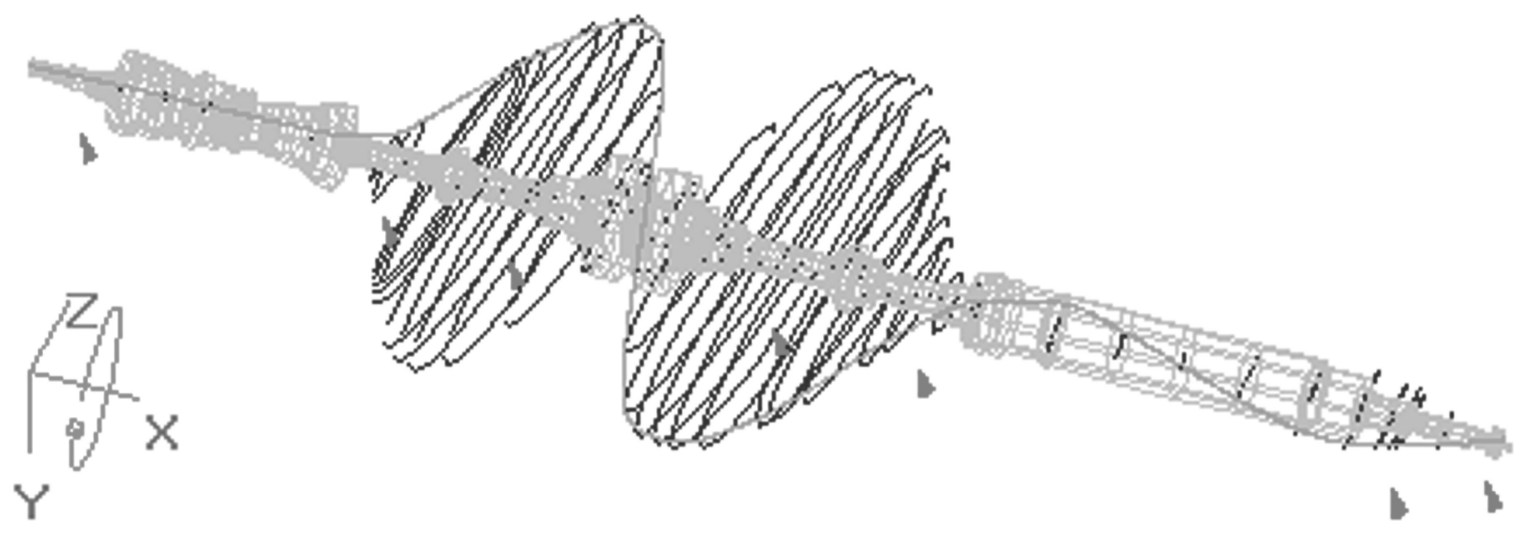

FIGURE 4

320-MW turbogenerator model mode shape corresponding to LP turbine 2nd critical speed in horizontal direction. 


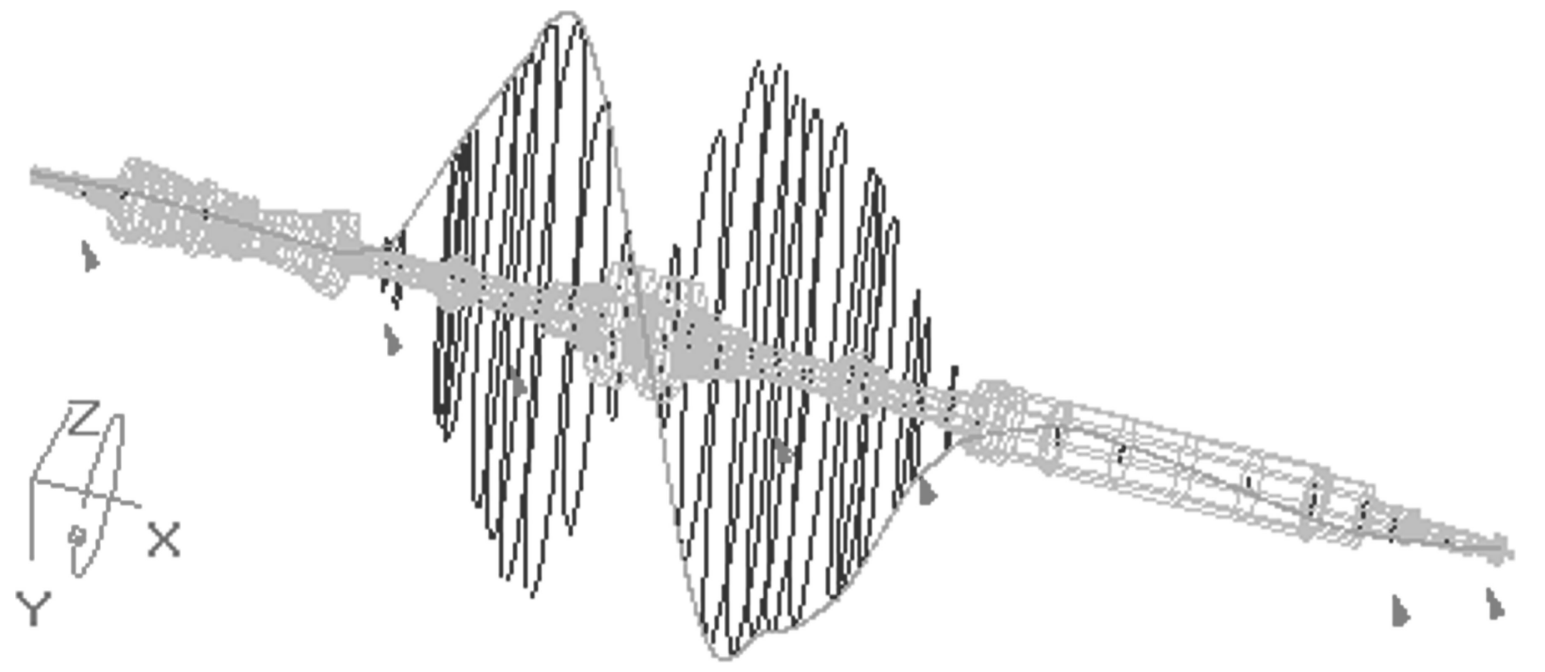

FIGURE 5

320-MW turbogenerator model mode shape corresponding to LP turbine 2nd critical speed in vertical direction.

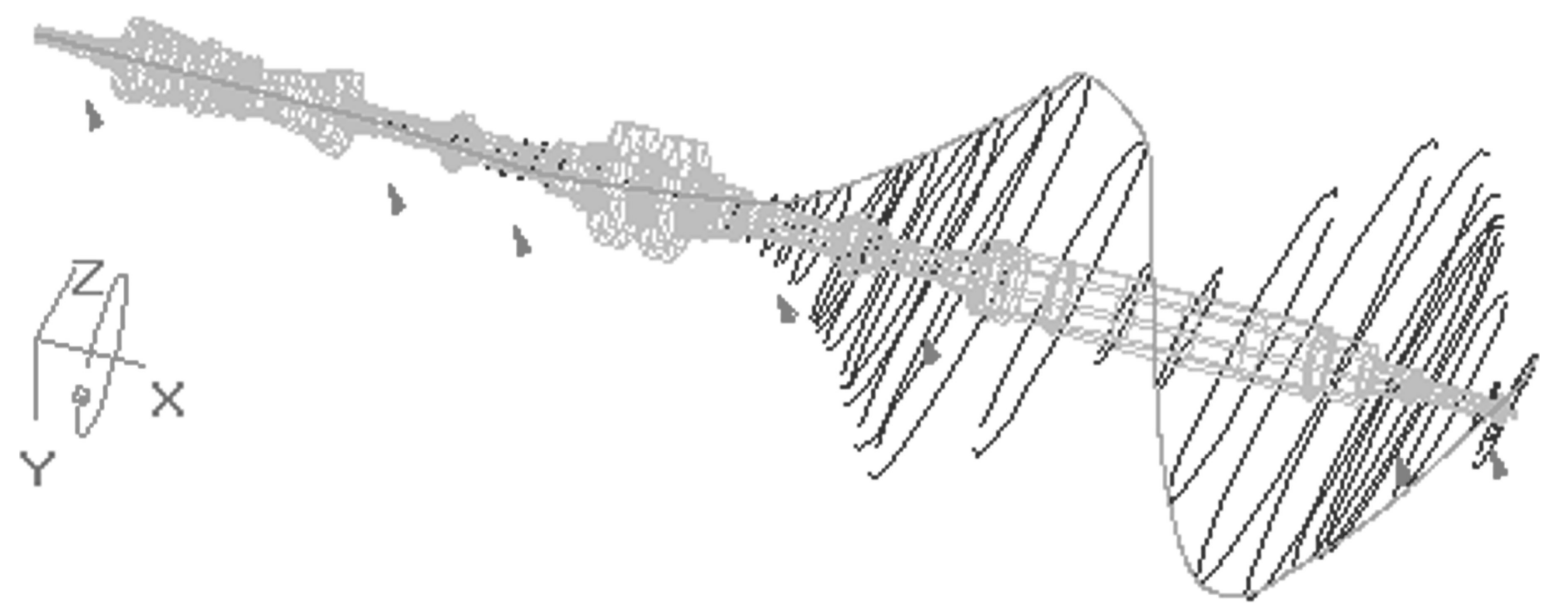

FIGURE 6

320-MW turbogenerator model mode shape corresponding to generator 2 nd critical speed in horizontal direction.

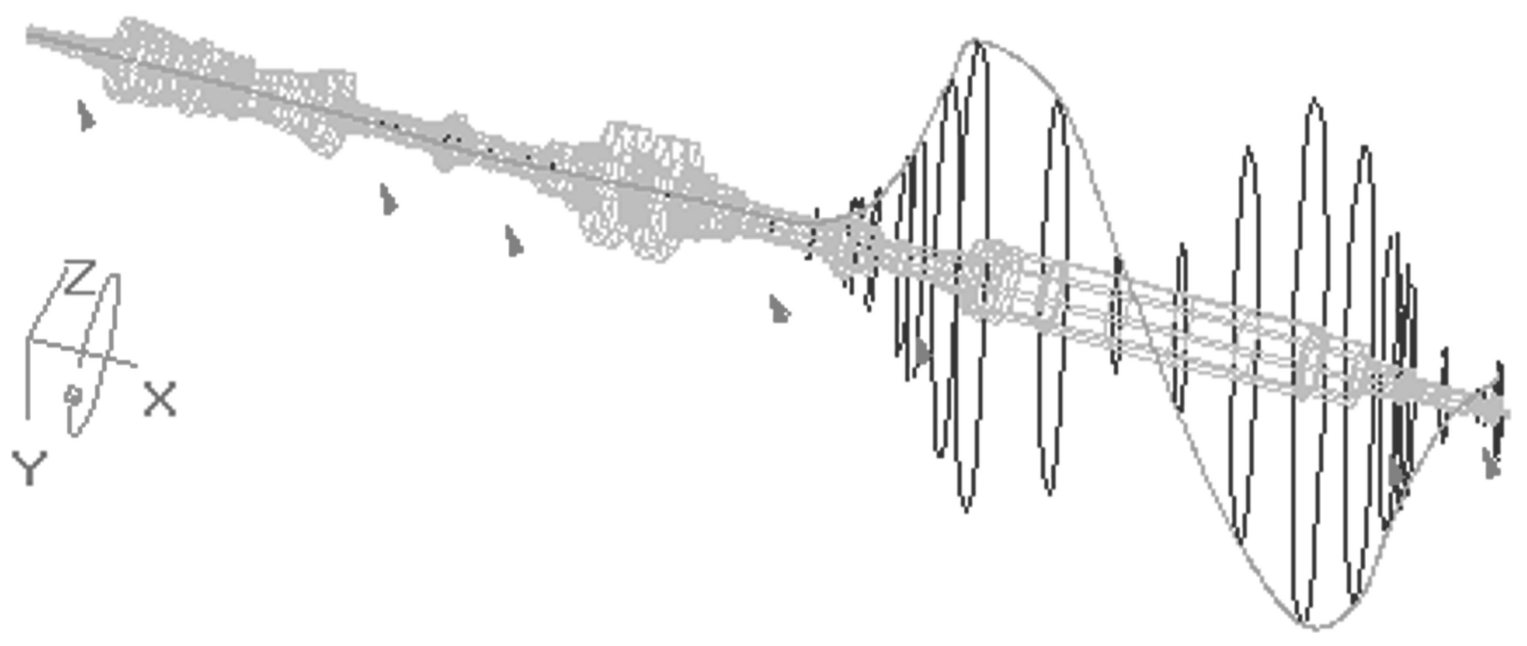

FIGURE 7

320-MW turbogenerator model mode shape corresponding to generator 2 nd critical speed in vertical direction. 


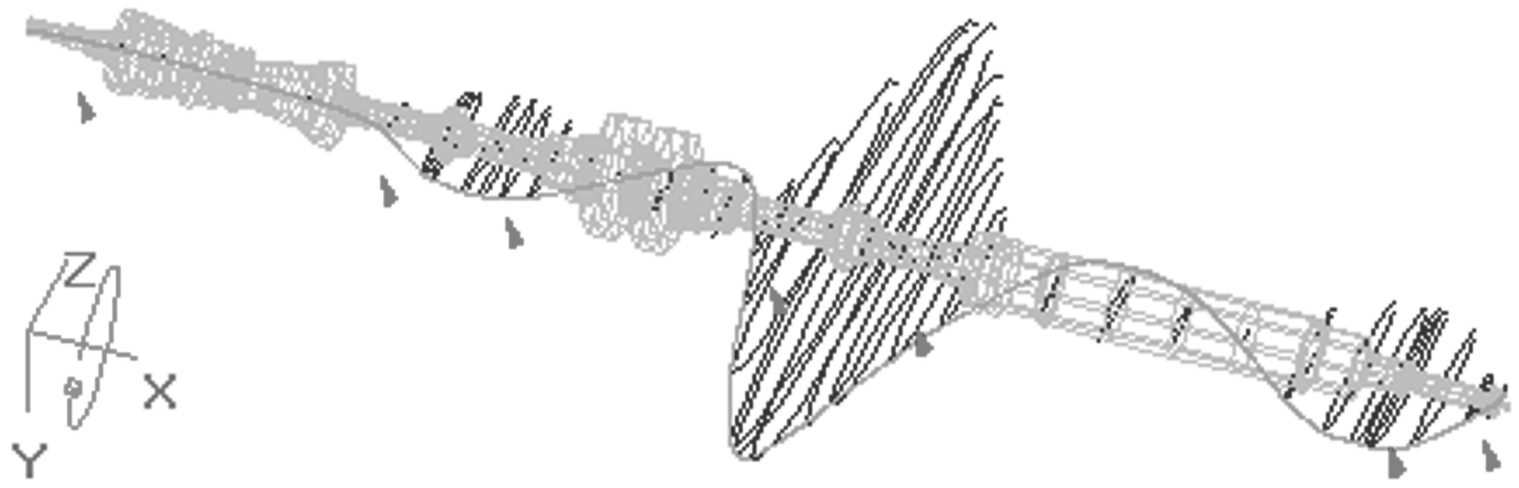

FIGURE 8

320-MW turbogenerator model mode shape corresponding to mode with maximum on the coupling between the LP turbine and the generator.

The unbalance identification results are shown in Table 3, where also the weights used for the horizontal and vertical measures in the bearings are reported. The differences in the amplitude between the balancing mass and the identified unbalance are normalized to the balancing mass value, while the phases to $180^{\circ}$, i.e., a $100 \%$ error, is a $180^{\circ}$ phase error.

As an example, Figure 9, shows the residues along the rotor for the last case in Table 3, with model E. Note the sharp minimum corresponding to the node of the identified fault.
The comparisons between experimental and calculated results, for bearing \#3, \#4, \#5, and \#6, using the parameters of the identified fault in last this case, are shown in Figures 10 to 13. The results can be deemed as good in the vertical direction, while in the horizontal direction the calculated results generally underestimate the amplitude corresponding to the second critical speed even with a good behavior on the phase.

The results summarized in Table 3 can be considered as acceptable, in particular also the use of the no-tuned model A

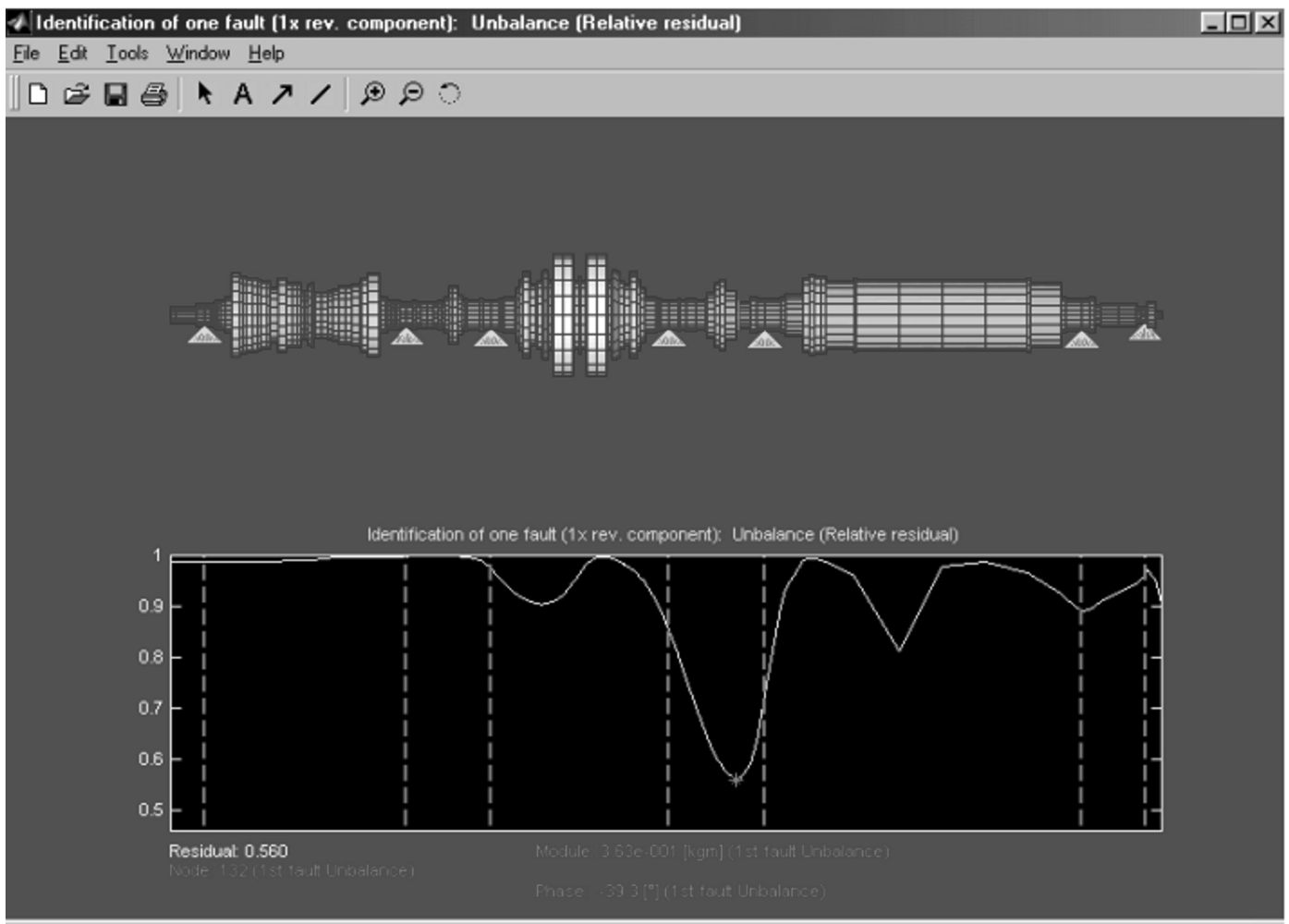

FIGURE 9

Unbalance identification. Residue along the rotor as calculated by ADVANT. 
TABLE 2

Experimental and model critical speeds for the mode with maximum on coupling LP-generator

\begin{tabular}{lrc}
\hline & $\mathrm{H}$ & $\mathrm{V}$ \\
\hline Experimental & $>3000$ & $>3000$ \\
Model A & $>5000$ & $>5000$ \\
Model B & 4220 & $>5000$ \\
Model C & 4170 & $>5000$ \\
Model D & 4150 & $>5000$ \\
Model E & 4140 & $>5000$ \\
\hline
\end{tabular}

allowed to identify correctly the position of the fault and its phase, even if the amplitude is overestimated, while the use of few measuring points (as in last case with model D) gives completely wrong results.

Better results could have been obtained by means of a more accurate tuning of the models that was not possible due to the difficulty of determining some of the critical speeds in the experimental data. However, the position of the fault is always identified with high accuracy, while the error in the phase is never greater than $20^{\circ}$. The identified amplitude results more sensitive to the model tuning and to the rotating speed set, but the error is acceptable under an engineering point of view.

TABLE 3

Unbalance identification results

\begin{tabular}{|c|c|c|c|c|c|c|c|c|c|c|c|c|c|c|c|c|}
\hline \multirow[b]{2}{*}{ Model } & \multirow{2}{*}{$\begin{array}{c}\text { Rotating speed } \\
\text { set [rpm] }\end{array}$} & \multicolumn{8}{|c|}{ Weights on the brg. meas. } & \multirow{2}{*}{$\begin{array}{l}\text { Meas. } \\
\text { section }\end{array}$} & \multirow[b]{2}{*}{ Node } & \multirow{2}{*}{$\begin{array}{l}\text { Ampl. } \\
{[\mathrm{kgm}]}\end{array}$} & \multirow{2}{*}{$\begin{array}{c}\Delta \\
\text { ampl. }\end{array}$} & \multirow[b]{2}{*}{ Phase } & \multirow{2}{*}{$\begin{array}{c}\Delta \\
\text { phase }\end{array}$} & \multirow[b]{2}{*}{ Residue } \\
\hline & & & 1 & 2 & 3 & 4 & 5 & 6 & 7 & & & & & & & \\
\hline \multicolumn{10}{|c|}{ Actual unbalance } & & 132 & 0.256 & & $-22.5^{\circ}$ & & \\
\hline \multirow[t]{2}{*}{ Model A } & \multirow{2}{*}{$\begin{array}{l}\text { All the } \\
\text { available }\end{array}$} & $\mathrm{H}$ & 1 & 1 & 1 & 1 & 1 & 1 & 1 & \multirow[t]{2}{*}{ Brg. } & \multirow[t]{2}{*}{132} & \multirow[t]{2}{*}{0.720} & \multirow{2}{*}{$181 \%$} & \multirow[t]{2}{*}{-28.4} & \multirow[t]{2}{*}{$-3 \%$} & \multirow[t]{2}{*}{0.607} \\
\hline & & $\mathrm{V}$ & 1 & 1 & 1 & 1 & 1 & 1 & 1 & & & & & & & \\
\hline \multirow[t]{2}{*}{ Model B } & \multirow{2}{*}{$\begin{array}{l}\text { All the } \\
\text { available }\end{array}$} & $\mathrm{H}$ & 1 & 1 & 1 & 1 & 1 & 1 & 1 & \multirow[t]{2}{*}{ Brg. } & \multirow[t]{2}{*}{131} & \multirow[t]{2}{*}{0.290} & \multirow[t]{2}{*}{$13 \%$} & \multirow[t]{2}{*}{$-35.8^{\circ}$} & $-7 \%$ & 0.710 \\
\hline & & $\mathrm{V}$ & 1 & 1 & 1 & 1 & 1 & 1 & 1 & & & & & & & \\
\hline Model B & 1500,2000 & $\mathrm{H}$ & 0.5 & 0.5 & 1 & 1 & 1 & 1 & 0.5 & Brg. & 131 & 0.535 & $109 \%$ & $-36.7^{\circ}$ & $-8 \%$ & 0.600 \\
\hline & 2500,3000 & $\mathrm{~V}$ & 0.5 & 0.5 & 1 & 1 & 1 & 1 & 0.5 & & & & & & & \\
\hline Model C & All the & $\mathrm{H}$ & 0.1 & 0.1 & 1 & 1 & 1 & 1 & 0.1 & Brg. & 133 & 0.143 & $-44 \%$ & $-15.0^{\circ}$ & $4 \%$ & 0.810 \\
\hline & available & $\mathrm{V}$ & 0.1 & 0.1 & 1 & 1 & 1 & 1 & 0.1 & & & & & & & \\
\hline Model C & 1500,2000 & $\mathrm{H}$ & 0.1 & 0.1 & 1 & 1 & 1 & 1 & 0.1 & Brg. & 132 & 0.366 & $43 \%$ & $-34.2^{\circ}$ & $-7 \%$ & 0.672 \\
\hline & 2500,3000 & $\mathrm{~V}$ & 0.1 & 0.1 & 1 & 1 & 1 & 1 & 0.1 & & & & & & & \\
\hline Model D & All the & $\mathrm{H}$ & 0 & 1 & 1 & 1 & 1 & 1 & 0 & M. s. & 133 & 0.212 & $-17 \%$ & $-27.5^{\circ}$ & $-3 \%$ & 0.685 \\
\hline & available & $\mathrm{V}$ & 0 & 1 & 1 & 1 & 1 & 1 & 0 & & & & & & & \\
\hline Model D & 1500,2000 & $\mathrm{H}$ & 0.1 & 0.1 & 1 & 1 & 1 & 1 & 0.1 & Brg. & 132 & 0.385 & $50 \%$ & $-36.8^{\circ}$ & $-8 \%$ & 0.657 \\
\hline & 2500,3000 & $\mathrm{~V}$ & 0.1 & 0.1 & 1 & 1 & 1 & 1 & 0.1 & & & & & & & \\
\hline Model D & 1500,2000 & $\mathrm{H}$ & 0.1 & 0.1 & 1 & 1 & 1 & 1 & 0.1 & M. s. & 132 & 0.339 & $32 \%$ & $-39.8^{\circ}$ & $-10 \%$ & 0.588 \\
\hline & 2500,3000 & $\mathrm{~V}$ & 0.1 & 0.1 & 1 & 1 & 1 & 1 & 0.1 & & & & & & & \\
\hline Model D & 1500,2000 & $\mathrm{H}$ & 0.1 & 1 & 1 & 1 & 1 & 1 & 0.1 & M. s. & 133 & 0.358 & $40 \%$ & $-40.7^{\circ}$ & $-10 \%$ & 0.567 \\
\hline & 2500,3000 & $\mathrm{~V}$ & 0.1 & 1 & 1 & 1 & 1 & 1 & 0.1 & & & & & & & \\
\hline Model D & 1500,2000 & $\mathrm{H}$ & 0 & 0 & 0 & 0 & 0 & 0 & 0 & M. s. & 50 & 0.0967 & $-62 \%$ & $-42.6^{\circ}$ & $-11 \%$ & 0.704 \\
\hline & 2500,3000 & $\mathrm{~V}$ & 0 & 1 & 1 & 1 & 1 & 1 & 0 & & & & & & & \\
\hline Model E & All the & $\mathrm{H}$ & 0 & 1 & 1 & 1 & 1 & 1 & 1 & M. s. & 133 & 0.188 & $-27 \%$ & $-23.8^{\circ}$ & $-1 \%$ & 0.740 \\
\hline & available & $\mathrm{V}$ & 0 & 1 & 1 & 1 & 1 & 1 & 1 & & & & & & & \\
\hline Model E & 1500,2000 & $\mathrm{H}$ & 0 & 1 & 1 & 1 & 1 & 1 & 0 & M. s. & 132 & 0.363 & $42 \%$ & $-39.3^{\circ}$ & $-9 \%$ & 0.560 \\
\hline & 2500,3000 & $\mathrm{~V}$ & 0 & 1 & 1 & 1 & 1 & 1 & 0 & & & & & & & \\
\hline
\end{tabular}

Brg.: measuring plane in the middle of the bearing; M. s.: measuring plane as close as possible to the actual one. 
TABLE 4

Rotor rub case-experimental critical speeds for the turbines and the generator

\begin{tabular}{|c|c|c|c|c|c|c|c|c|c|c|c|c|}
\hline & \multicolumn{4}{|c|}{ HP-IP turbine } & \multicolumn{4}{|c|}{ LP turbine } & \multicolumn{4}{|c|}{ Generator } \\
\hline & \multicolumn{2}{|c|}{$1 \mathrm{st}$} & \multicolumn{2}{|c|}{2 nd } & \multicolumn{2}{|c|}{$1 \mathrm{st}$} & \multicolumn{2}{|c|}{ 2nd } & \multicolumn{2}{|c|}{$1 \mathrm{st}$} & \multicolumn{2}{|c|}{ 2nd } \\
\hline & $\mathrm{H}$ & $\mathrm{V}$ & $\mathrm{H}$ & $\mathrm{V}$ & $\mathrm{H}$ & $\mathrm{V}$ & $\mathrm{H}$ & $\mathrm{V}$ & $\mathrm{H}$ & $\mathrm{V}$ & $\mathrm{H}$ & $\mathrm{V}$ \\
\hline Rubbing turbogenerator & $?$ & 2020 & $?$ & $?$ & 1000 & 1460 & 2200 & 2870 & 833 & $?$ & 1800 & $?$ \\
\hline Similar turbogenerator & 1300 & 1800 & $?$ & $?$ & $?$ & 1440 & $?$ & $>3000$ & 1010 & 1215 & 2200 & 2800 \\
\hline
\end{tabular}
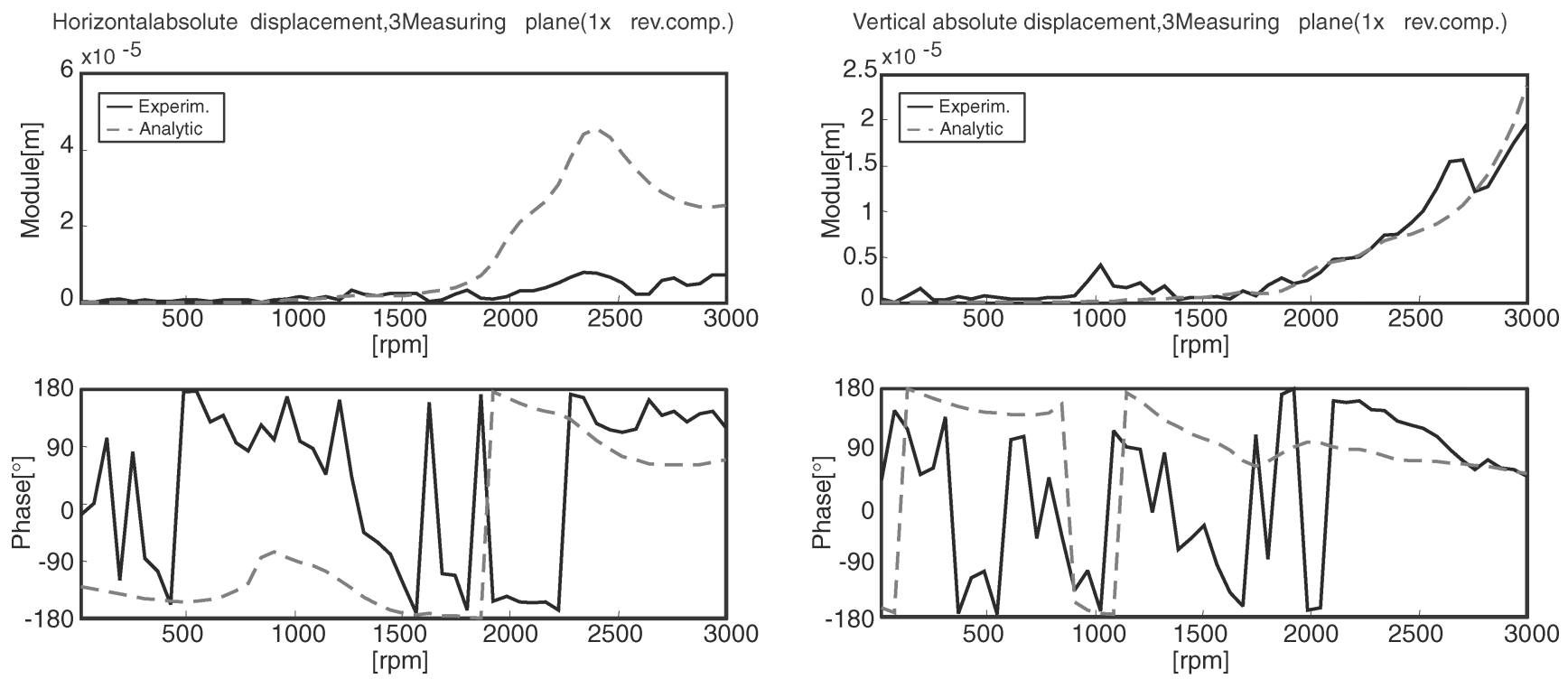

Horizontal

Vertical

FIGURE 10

Unbalance identification. Comparison between experimental and calculated results for bearing \#3.
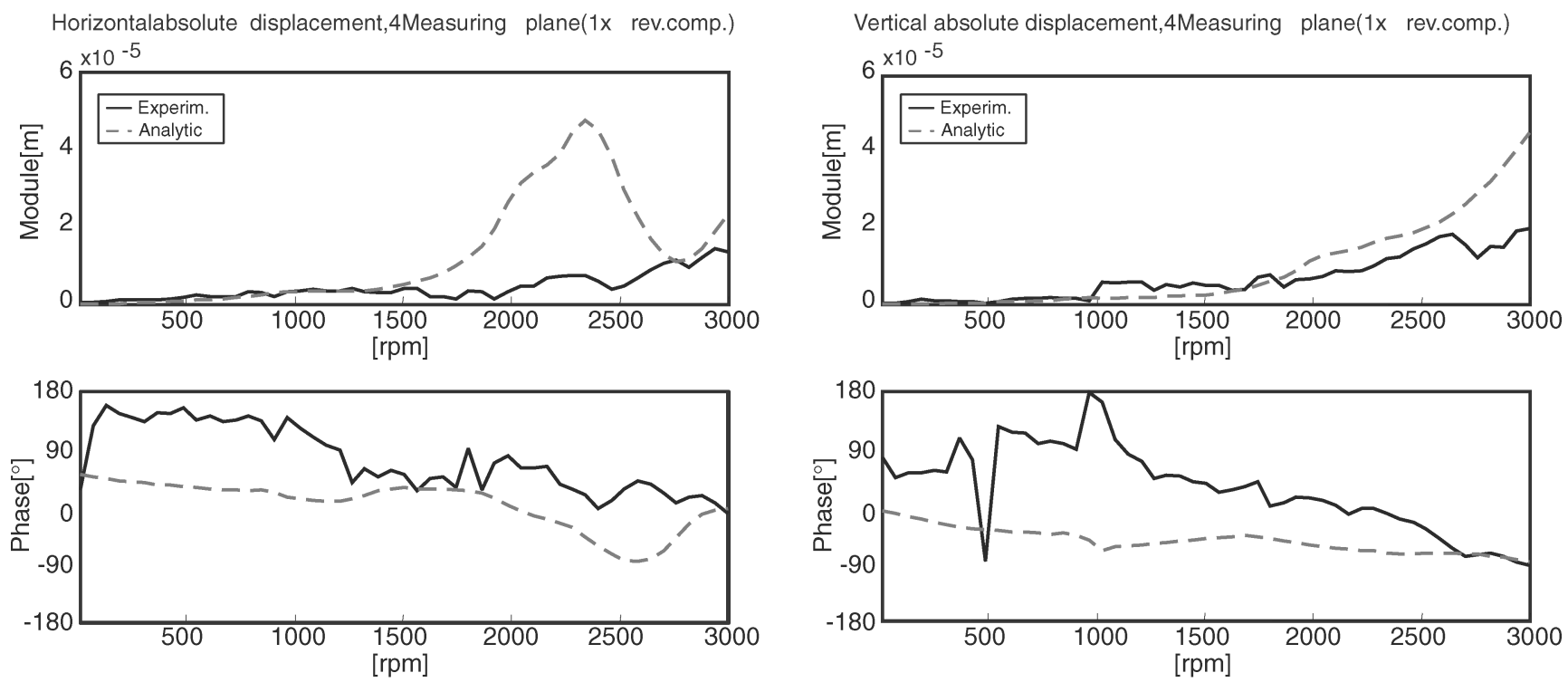

Horizontal

\section{Vertical}

FIGURE 11

Unbalance identification. Comparison between experimental and calculated results for bearing \#4. 

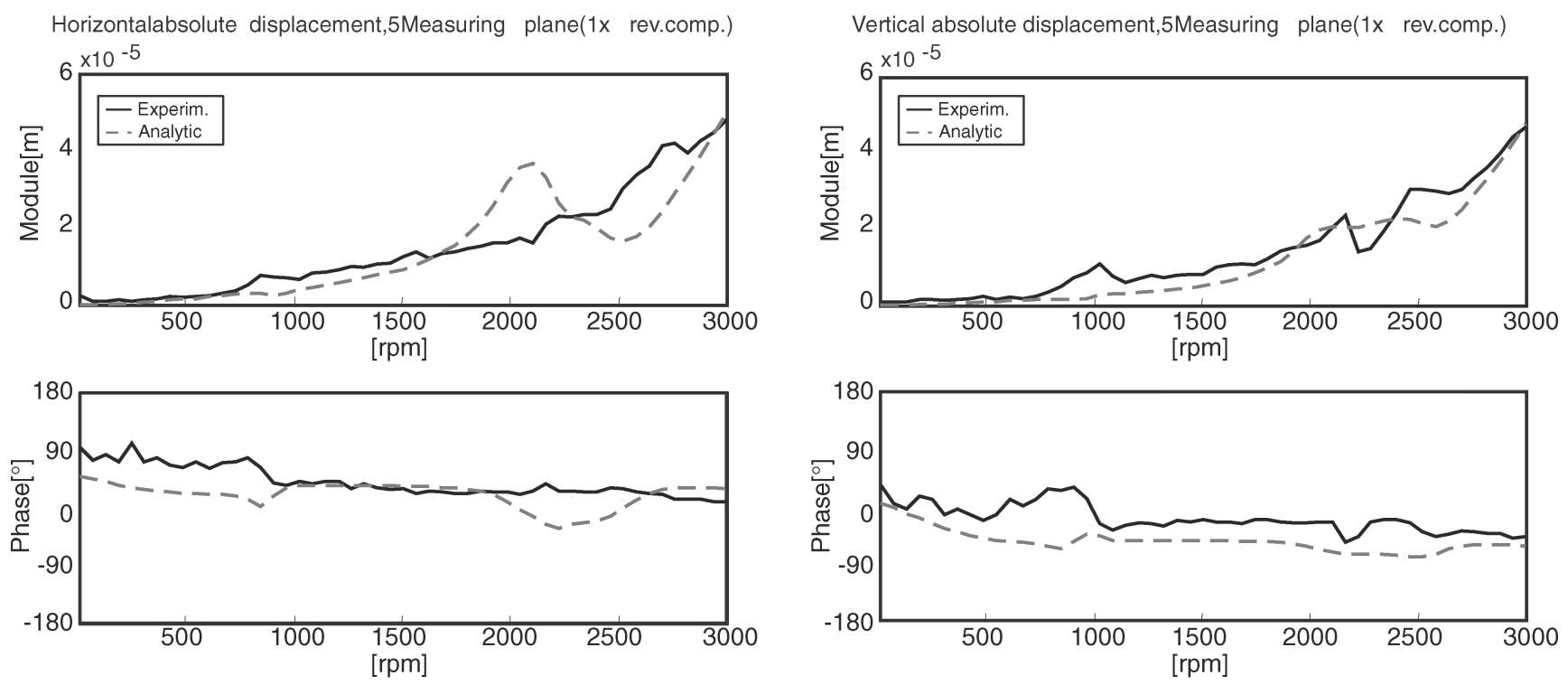

Horizontal

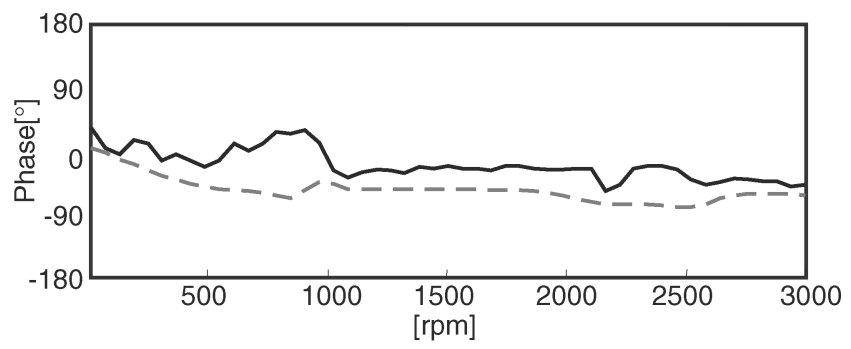

Vertical

FIGURE 12

Unbalance identification. Comparison between experimental and calculated results for bearing \#5.

\section{ROTOR RUB IDENTIFICATION ON A 320-MW TURBOGENERATOR}

The second case is related to another 320-MW turbogenerator (see Figure 14) composed of by two turbines (an HP-IP and a LP), and a generator connected by rigid couplings, on seven oil film bearings of which those on HP-IP turbine are bi-lobed and the others lemon-shaped, operating at a rated speed of $3000 \mathrm{rpm}$. The rotor, which also in this case is about $28 \mathrm{~m}$ long and has a mass of about $120 \mathrm{t}(22 \mathrm{t}$ for the HP-IP turbine, $52 \mathrm{t}$ for the LP turbine, and $46 \mathrm{t}$ for the generator), has been modeled by 132 f.e. beams. The bearing stiffness and damping coefficients are defined for the rotating speeds equal to 1000,2000 , and $3000 \mathrm{rpm}$, while the foundation is modeled by mass, spring, and damper systems, whose parameters are defined only at $3000 \mathrm{rpm}$ and therefore considered as constant for all the rotating speeds used for the identification.
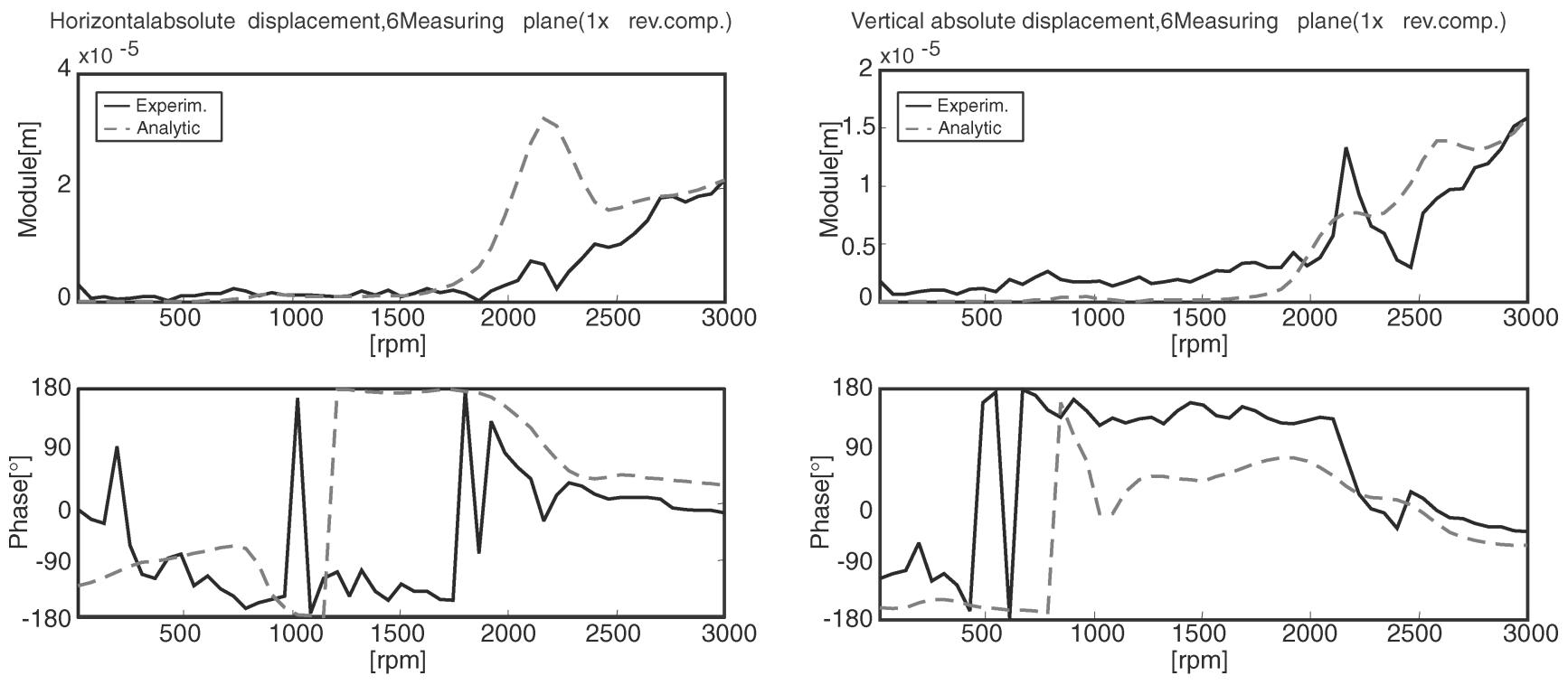

Horizontal

FIGURE 13

Unbalance identification. Comparison between experimental and calculated results for bearing \#6. 


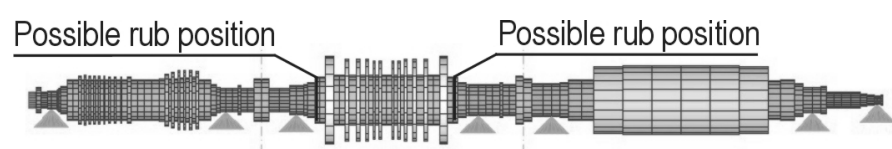

FIGURE 14

320-MW turbogenerator model used for unbalance identification.

The available experimental data are relative to two machine run-down, of which the first is considered as the reference case, the second instead was a consequence of a suspected rub. The analysis of the latter data indicates as possible rubbing sections the two sealing zones close to both last stages of the LP turbine (see Figure 14).

Also in this case it was not possible to fine tune the rotor model. In fact, neither the analysis of the two experimental data set on this turbogenerator nor those of a similar turbogenerator in another plant allowed the correct identification of all of the critical speeds as reported in Table 4. This notwithstanding, by combining these data, a model that can reproduce approximately the average speeds between those of the two similar turbogenerators has been implemented in ADVANT. No tuning was made on the modal dampings of the model.

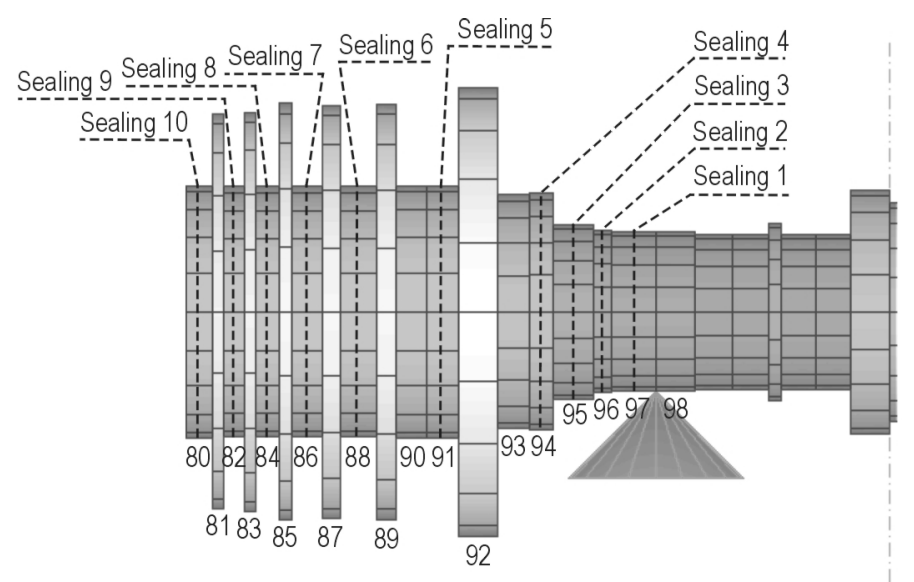

FIGURE 16

Sealing position on right-hand side of LP turbine.

First, an identification of a single local bow, corresponding to a rub, was performed. The results are reported in Figure 15 and show that the hypothesis of a rub in the last stage of a LP turbine close to bearing \#4 was confirmed. Figure 16 shows approximately, the positions of the sealings on the LP turbine

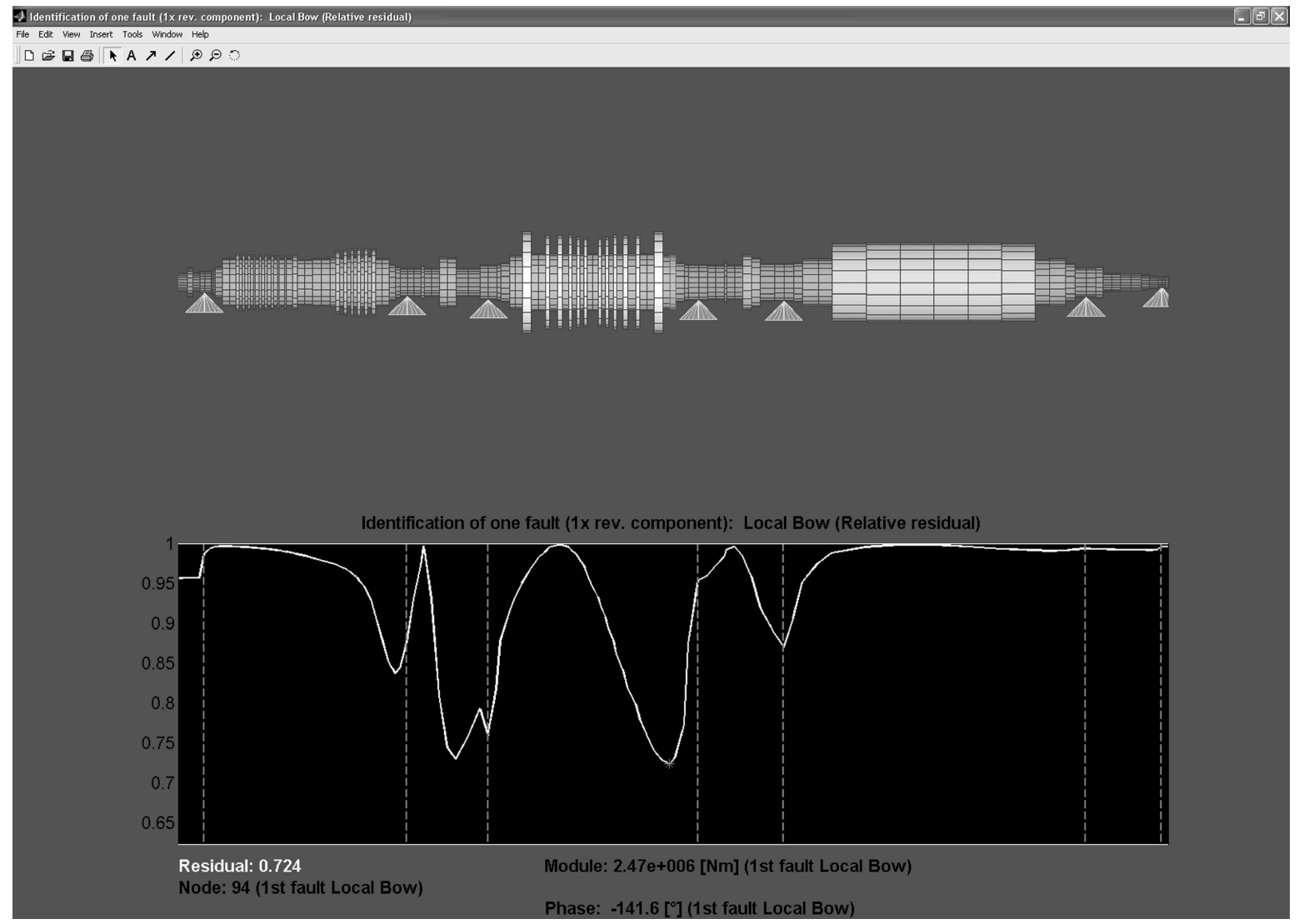

FIGURE 15

Residue along the rotor as calculated by ADVANT for a single rub. 


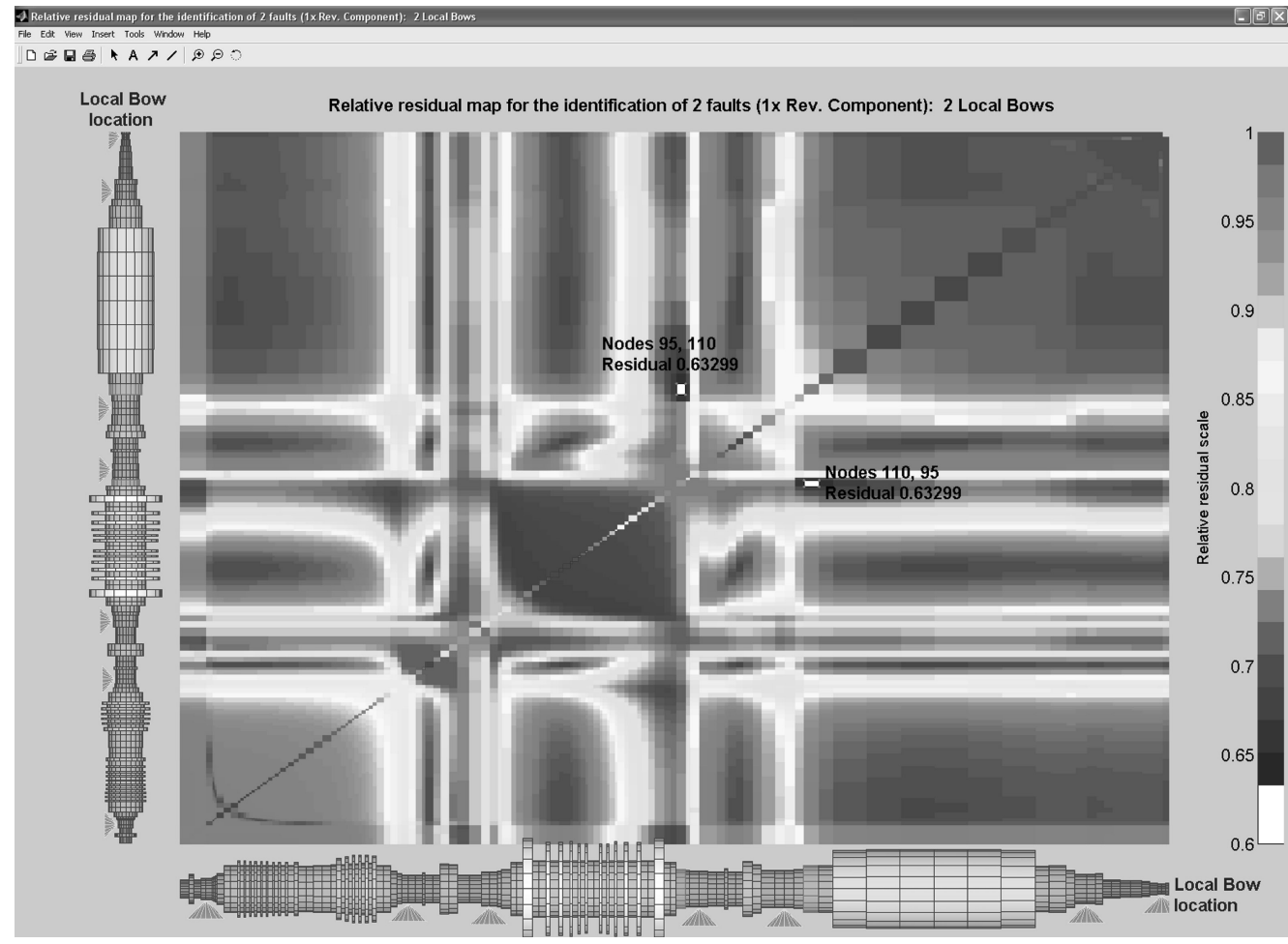

FIGURE 17

Residue map the rotor as calculated by ADVANT for a double rub.

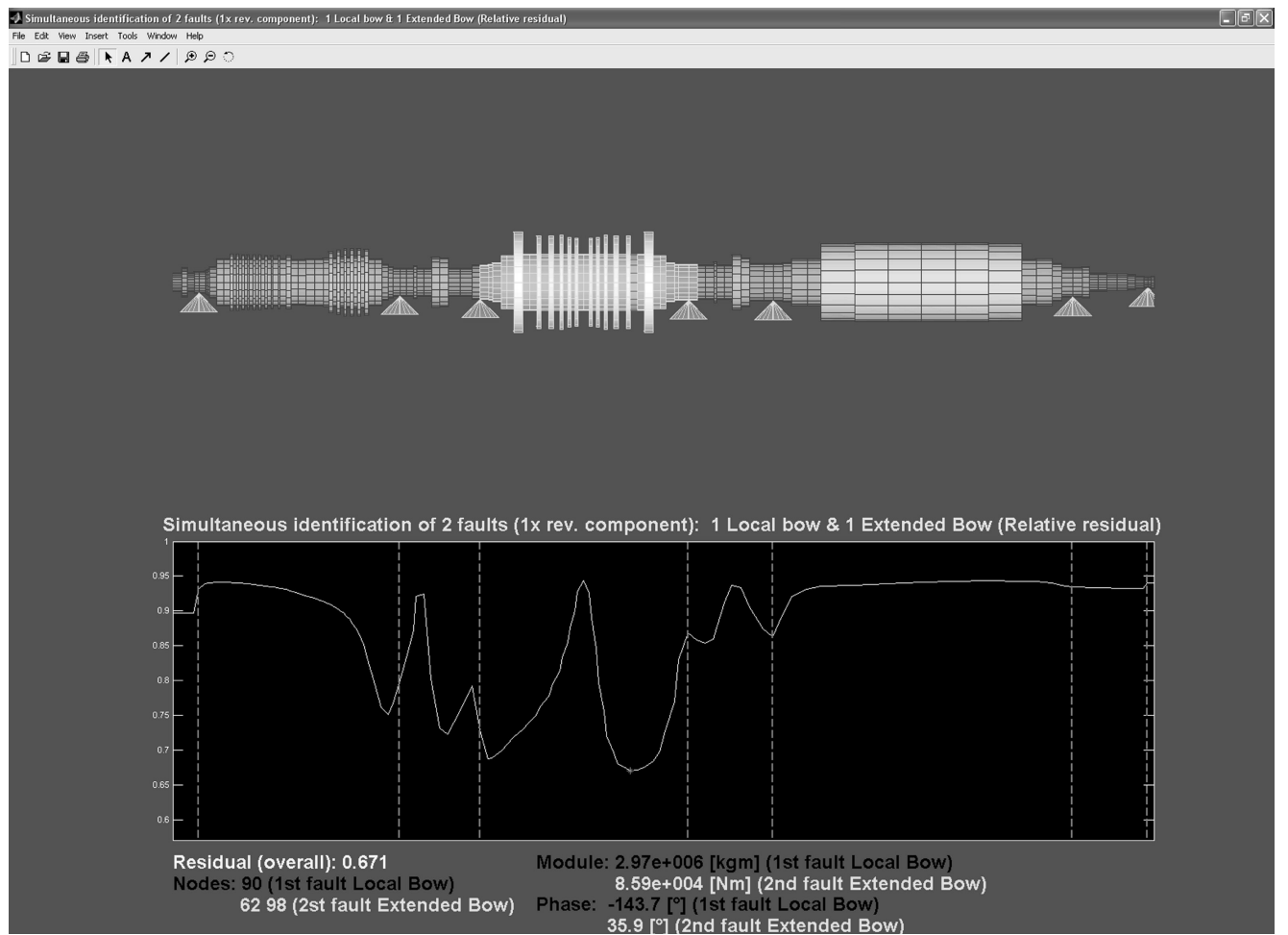

FIGURE 18

Residue along the rotor as calculated by ADVANT for a single rub and an extended bow. 

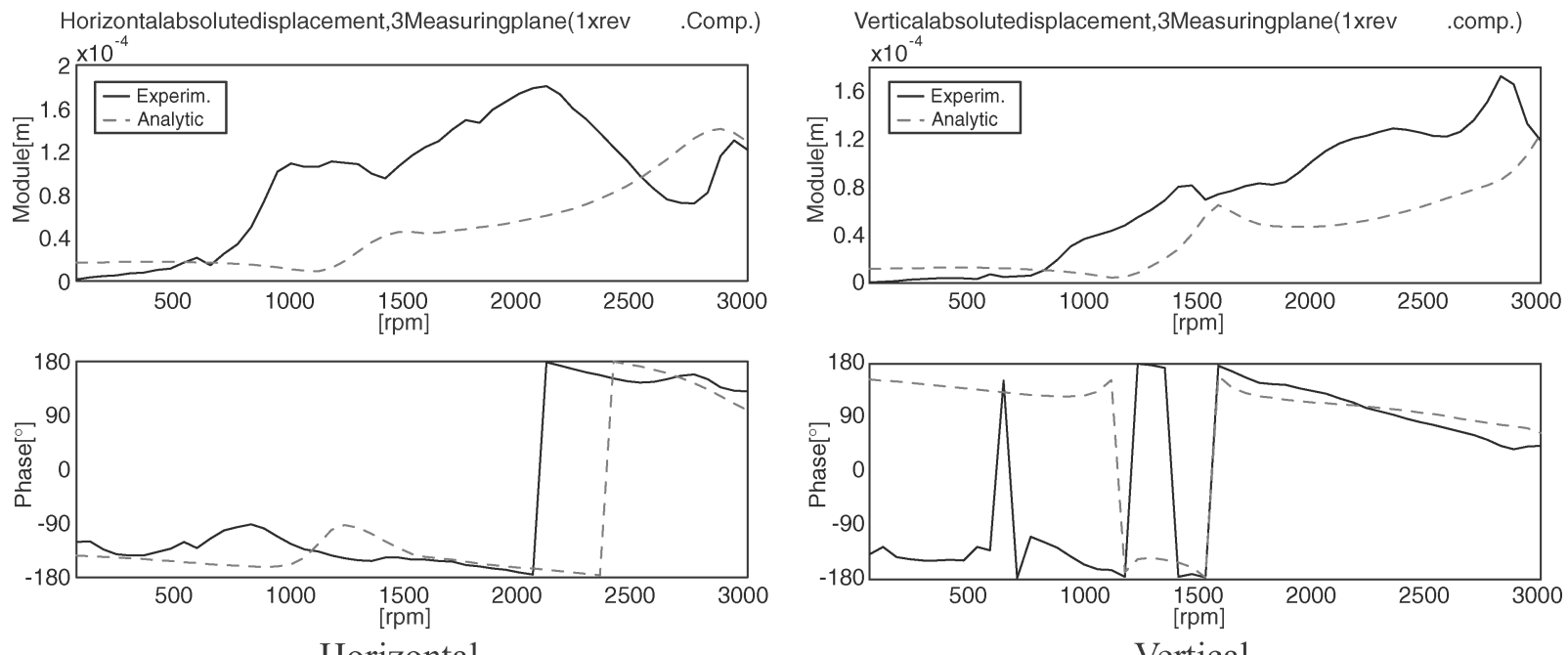

Horizontal

Vertical

FIGURE 19

Rub and bow identification. Comparison between experimental and calculated results for bearing \#3.

and it can be easy checked that sealing 4 is in the identified position of the rub.

Then, the identification of two local bows, looking also for a possible rub on the last stage of LP close to bearing \#3 was not successful, since the second local bow results located on the generator while the first is practically in the same section as before (see Figure 17) even if in this case the residue value is less than that of previous identification.

A further identification was made looking for a local bow (a rub) and an extended bow on a certain length of the rotor. The results, shown in Figure 18, show that the rub is again identified in sealing 5, close to the last stage of LP turbine, but also the LP turbine presents an extended bow. Also in this case, the residue value is less than that of a single local bow. Figures 19 and 20 show the comparison between experimental vibrations and calculated ones on the bearings of LP turbine. The agreement can be deemed as good, considering that the model is not tuned and that the quality of the experimental data is fair. The final validation of the identification procedure was obtained by the result of the visual inspection during the maintenance that indicates the rub in the sealing close to the LP last stage.
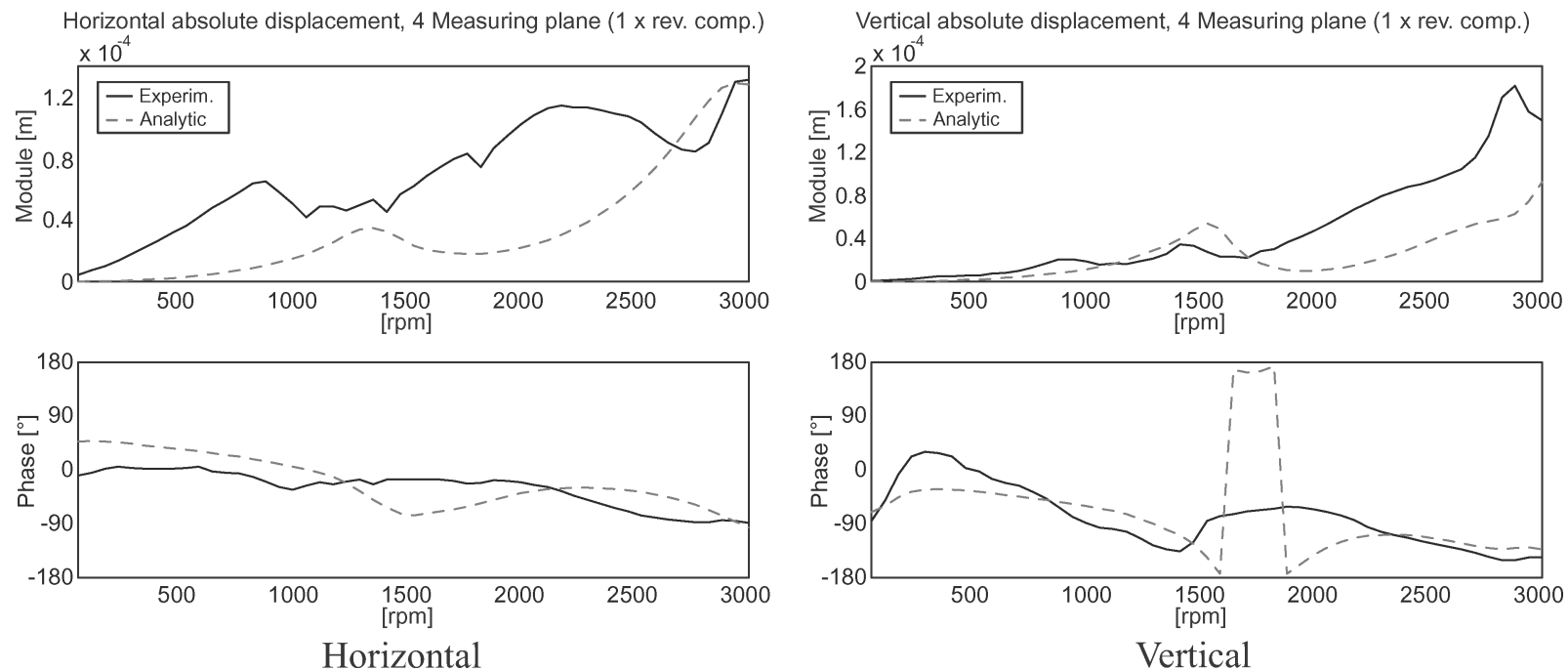

FIGURE 20

Rub and bow identification. Comparison between experimental and calculated results for bearing \#4. 


\section{CONCLUSIONS}

A multiple model-based fault identification method has been described and two successful interesting applications of the procedure, on experimental data of turbogenerators of power plants, have been shown. In the first case, data relative to a balancing on a 320-MW turbogenerator was used and some considerations were presented in regards to the choice of the rotating speed set for the identification. In the second case, the real machine, again a 320-MW turbogenerator of a different manufactures, presented a rub in sealing and the proposed method allowed us to identify the position of the rub, as confirmed by following maintenance inspection on the machine. In both cases the proposed technique was effective in detecting the fault, even if the model of the machines were not fine tuned, as often occurs in the case of real machines.

\section{ACKNOWLEDGMENTS}

This work is partially funded by the MURST (Italian Ministry for the University and Scientific Research) Cofinanziamento "Identificazione di Malfunzionamenti in Sistemi Meccanici" for the year 1999 .

\section{NOMENCLATURE}

$\mathbf{A}^{(k)} \quad$ complex vector of the $k$ th fault

D damping matrix

$d \mathbf{D} \quad$ damping matrix change due to faults

$d \mathbf{K} \quad$ stiffness matrix change due to faults

$d \mathbf{M} \quad$ mass matrix change due to faults

$[\mathbf{E}(n \Omega)] \quad$ system dynamical stiffness matrix

F force vector

$\mathbf{F}_{f} \quad$ force vector due to faults

$\mathbf{F}_{f n} \quad n$th force vector harmonic component due to faults

$\left[\mathbf{F}_{L}^{(k)}\right] \quad$ localization vector of the $k$ th fault

$F \quad$ force amplitude

K stiffness matrix

M moment vector, mass matrix

$\mathbf{M}_{u} \quad$ original bow of the rotor

$M \quad$ moment amplitude

$m \quad$ number of faults, unbalance mass

$n \quad$ number of the harmonic component

$r \quad$ distance of the unbalance mass from the rotating axis

$\mathbf{U} \quad$ original unbalance of the rotor

W rotor weight

$\mathbf{X} \quad$ vector of vibration harmonic component

$\mathbf{X}_{\mathrm{A} n} \quad$ partition of $\mathbf{X}_{n}$ for the nodes not corresponding to measuring points

$\mathbf{X}_{\mathrm{B} n} \quad$ partition of $\mathbf{X}_{n}$ for the nodes corresponding to measuring points

$\mathbf{X}_{n} \quad n$th vibration harmonic component

$\mathbf{X}_{s t} \quad$ static deformation

$\mathbf{x} \quad$ vibration due to fault only

$\mathbf{x}_{t} \quad$ rotor total vibration

$\mathbf{x}_{1} \quad$ vibration due to weight original unbalance and bow

\begin{tabular}{|c|c|}
\hline$z$ & rotor axial abscissa \\
\hline $\boldsymbol{\alpha}_{n}$ & inverse of $[\mathbf{E}(n \Omega)]$ \\
\hline$\alpha_{\mathrm{B} n}$ & $\begin{array}{l}\text { partition of } \boldsymbol{\alpha}_{n} \text { for the nodes corresponding to mea- } \\
\text { suring points }\end{array}$ \\
\hline $\boldsymbol{\alpha}_{\mathrm{A} n}$ & $\begin{array}{l}\text { partition of } \boldsymbol{\alpha}_{n} \text { for the nodes not corresponding to } \\
\text { measuring points }\end{array}$ \\
\hline $\overrightarrow{\boldsymbol{\delta}}_{n}$ & $\begin{array}{l}\text { difference between calculated and measured vibra- } \\
\text { tions }\end{array}$ \\
\hline$\delta_{r n}$ & relative residue \\
\hline$\varphi$ & phase \\
\hline$\vec{\Omega}$ & vector of rotating speeds \\
\hline$\Omega$ & rotating speed, frequency \\
\hline
\end{tabular}

\section{REFERENCES}

Bachschmid, N., Vania, A., Tanzi, E., and Pennacchi, P. 1999. Identification and simulation of faults in rotor systems: experimental results. EURO DINAME 99-Dynamic Problems in Mechanics and Mechatronics, Wissenschaftszentrum Schloß Reisenburg der Universität Ulm, July 11-16, Günzburg, Germany, 3-11.

Bachschmid, N., and Pennacchi, P. 2000. Model based malfunction identification from bearing measurements. IMechE-7th International Conference on Vibrations in Rotating Machinery, September 12-14, University of Nottingham, UK, 571-580.

Bachschmid, N., Pennacchi, P., Tanzi, E., and Vania, A. 2000a. Accuracy of modelling and identification of malfunctions in rotor systems: experimental results. Journal of the Brazilian Society of Mechanical Sciences XXII, 3:423-442.

Bachschmid, N., Pennacchi, P., Tanzi, E., and Audebert, S. 2000b. Identification of transverse cracks in rotors systems. ISROMAC-8 Conference, March 26-30, Honolulu, Hawaii, 1065-1072.

Bachschmid, N., Pennacchi, P., and Audebert, S. 2000c. Some results in model based transverse crack identification in rotor systems. CONEM 2000-Congreso Nacional de Engenharia Mecànica, August 7-11, Natal, Rio Grande do Norte, Brasil.

Bachschmid, N., Pennacchi, P., Tanzi, E., and Vania, A. 2000d. Identification of transverse crack position and depth in rotor systems. Meccanica, International Journal of the Italian Association of Theoretical and Applied Mechanics 35(6):563-582.

Bachschmid, N., Pennacchi, P., and Vania, A. 2001. Spiral vibrations due to rub: numerical analysis and field experiences. Schwingungen in Rotierenden Maschinen $V$ Vieweg Verlag, Braunschweig/Weisbaden, Germany, 61-74.

Bachschmid, N., Pennacchi, P., and Vania, A. 2002. Identification of multiple faults in rotor systems. Journal of Sound and Vibration 254(2):327-366.

Chen, P. Y. P., Feng, N., and Hahn, E. J. 2001. Flexible rotor balancing taking bearing nonlinearity into account. ASME 2001 Design Engineering Technical Conferences and Computers and Information in Engineering Conference, September 9-12, Pittsburgh, Pennsylvania.

Edwards, S., Lees, A. W., and Friswell, M. I. 2000. Estimating rotor unbalance from a single run-down, IMechE-7th International Conference on Vibrations in Rotating Machinery, September 12-14, University of Nottingham, UK, 323-334.

Gregori, L., Provasi, R., and Zanetta, G. A. 2000. Automated procedure for vibration monitoring of large rotating machinery in power plants. IMechE-7th International Conference on Vibrations in Rotating Machinery, September 12-14, University of Nottingham, UK, 657-666. 
Gregori, L., and Zanetta, G. A. 2001. Signal forecasting in the vibration monitoring of large rotating machinery in power plants. Survelliance 4-Acoustical and Vibratory Surveillance Methods and Diagnostic Techniques, October 16-18, Compiegne, France, 599-609.

Isermann, R. 1995. Fault detection and diagnosis-methods and applications, 2nd International Symposium on Acoustical and Vibratory Surveillance Methods and Diagnostic Techniques, October 10-12, Senlis, France.

Kellenberger, W. 1980. Spiral vibrations due to the seal rings in turbogenerators. Thermally Induced Interaction between Rotor and Stator. Journal of Mechanical Design 102:177-184.

Kreuzinger-Janik, T., and Irretier, H. 2000. Unbalance identification of flexible rotors based on experimental modal analysis. IMechE7th International Conference on Vibrations in Rotating Machinery, September 12-14, University of Nottingham, UK, 335-346.

Liebich, R. 1998. Rub induced nonlinear vibrations considering the Thermo-elastic effect. IFToMM Fifth International Conference on Rotor Dynamics, Darmstad, Germany.

Markert, R., Platz, R., and Siedler, M. 2000. Model based fault identification in rotor systems by least squares fitting. ISROMAC-8 Conference, March 26-30, Honolulu, Hawaii, 901-915.

Mayes, I., and Penny, J. E. T. 1999. Model based diagnostics of faults in rotating machines. 12th International Congress on Condition Mon- itoring and Diagnostic Engineering Management-COMADEM 99 Sunderland, UK.

Patton, R. J., Simani, S., Daley, S., and Pike, A. 2001. Identification and model-based fault diagnosis of a gas turbine system. Survelliance 4-Acoustical and Vibratory Surveillance Methods and Diagnostic Techniques, October 16-18, Compiegne, France, 27-48.

Platz, R., Markert, R., and Seidler, M. 2000. Validation of online diagnostics of malfunctions in rotor systems. IMechE-7th International Conference on Vibrations in Rotating Machinery, September 12-14, University of Nottingham, UK, 581-590.

Platz, R., and Markert, R. 2001. Fault models for on-line identification of malfunctions in rotor systems. Survelliance 4-Acoustical and Vibratory Surveillance Methods and Diagnostic Techniques, October 16-18, Compiegne, France, 435-446.

Vania, A., Bachschmid, N., and Pennacchi, P. 2001. Analysis of light rotor-to-stator contacts in large turbine-generator units. Survelliance 4-Acoustical and Vibratory Surveillance Methods and Diagnostic Techniques, October 16-18, Compiegne, France, 507516.

White, M. F., and Jecmenica, M. 1999. Fault diagnosis using a fault matrix incorporating fuzzy logic. 12th International Congress on Condition Monitoring and Diagnostic Engineering ManagementCOMADEM 99 Sunderland, UK. 

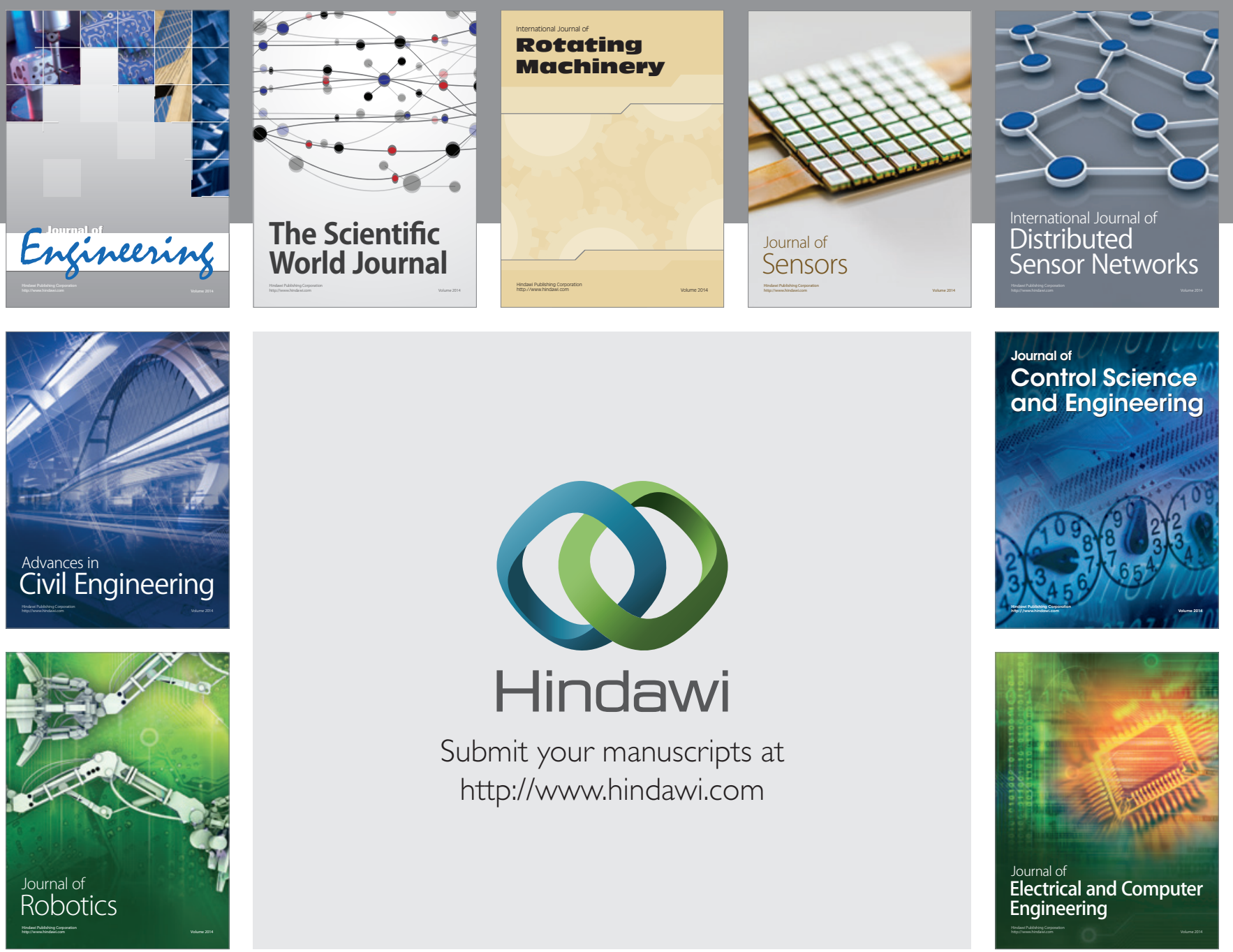

Submit your manuscripts at

http://www.hindawi.com
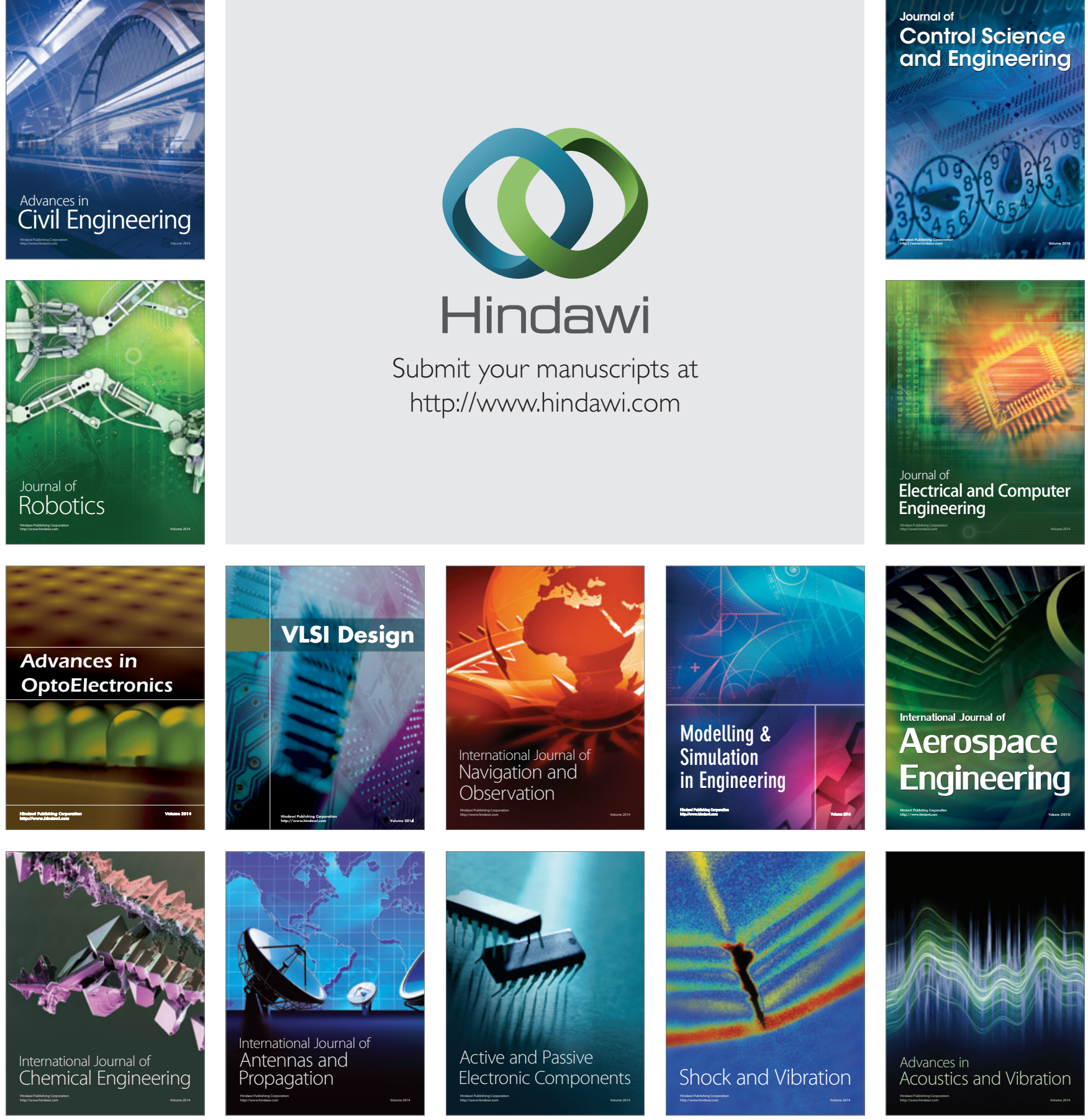